\title{
Modeling of mixed-solvent electrolyte systems
}

\author{
Saifuddin Ahmed ${ }^{\mathrm{a}, \mathrm{b}}$, Nicolas Ferrando ${ }^{\mathrm{a}}$, Jean-Charles de Hemptinne ${ }^{\mathrm{a}^{*}}$, Jean-Pierre Simonin ${ }^{\mathrm{b}}$, \\ Olivier Bernard $^{\mathrm{b}}$, Olivier Baudouin ${ }^{\mathrm{c}}$ \\ a IFP Energies Nouvelles, 1 et 4 Avenue de Bois-Préau, 92852 Rueil-Malmaison Cedex, France \\ b CNRS, Sorbonne Universités, UPMC Univ Paris o6, Laboratoire PHENIX, Case 51, 4 place Jussieu, F-75005 Paris, \\ France \\ ${ }^{\mathrm{c}}$ ProSim SA, Immeuble Stratège A, 51 rue Ampère, F-31670 Labege, France \\ * Corresponding author : jean-charles.de-hemptinne@ifpen.fr
}

\begin{abstract}
Models for mixed-solvent strong electrolytes, using an equation of state (EoS) are reviewed in this work. Through the example of ePPC-SAFT (that includes a Born term and ionic association), the meaning and the effect of each contribution to the solvation energy and the mean ionic activity coefficient are investigated. The importance of the dielectric constant is critically reviewed, with a focus on the use of a salt-concentration dependent function. The parameterization is performed using two adjustable parameters for each ion: a minimum approach distance $\left(\sigma_{M S A}\right)$ and an association energy $\left(\varepsilon^{A B}\right)$. These two parameters are optimized by fitting experimental activity coefficient and liquid density data, for all alkali halide salts simultaneously, in the range $298 \mathrm{~K}$ to $423 \mathrm{~K}$. The model is subsequently tested on a large number of available experimental data, including salting out of Methane/Ethane $/ \mathrm{CO}_{2} / \mathrm{H}_{2} \mathrm{~S}$. In all cases the deviations in bubble pressures were below 20\% AADP. Predictions of vapor-liquid equilibrium of mixed solvent electrolyte systems containing methanol, ethanol are also made where deviations in bubble pressures were found to be below $10 \%$ (AADP).
\end{abstract}

Keywords: electrolytes, mixed solvents, dielectric constant, ePPC-SAFT, salting-out.

\section{Introduction}

The biorefining industry involves the conversion of biomass or organic material into fuel grade biodiesel or bio-gasoline. The pre-treated biomass (feeding bio-refinery units) is a complex mixture of oxygenated hydrocarbons and water, a strongly polar solvent which forms a non-ideal mixture with the oxygenated chemicals. Water is also responsible for the degradation of processing equipment and worsening of product quality, so it needs to be separated. Aqueous solutions of salts have shown promising trend to aid in separation of these complex and oxygenated molecules encountered during the production processes of biofuel. The presence of an electrolyte causes a significant change in the equilibrium composition (especially liquid-liquid equilibrium), by altering the hydrogen bonding structure and other intermolecular forces. Hence, due to the addition of salt, the mutual solubilities change in either phase (aqueous phase and organic-rich phase). This behaviour is called the salting-out effect when the solubility decreases, and the salting-in effect when the solubility increases when adding salts $[1,2]$. This phenomenon is used in various industries (such as biorefining, pharmaceuticals or water treatment) for the separation of organic compounds. The use of electrolytes is however not limited to separation applications. They are often of interest in water treatment [3], geological, biological and 
petroleum industry [4][5]. Thermodynamic information is vital for various industrial processes. More specifically, chemical engineers need to know the phase equilibrium between species and enthalpies to accurately design separation processes such as distillation columns, extractive distillation, liquid-liquid extractions, etc. $[4,6,7]$. Due to the large number of species involved and varying operating conditions, accurate thermodynamic information is often missing, leading to inefficient design both in terms of energy efficiency and product purity. In this context, the development of a predictive thermodynamic equation of state is of primary importance $[4,7-12]$.

\section{Literature review}

Thermodynamic models for electrolytes are numerous. The development of these models can be dated back to the $70^{\prime}$ s $\left[13^{-15}\right]$. These models differ in applicability in terms of ranges of temperature and pressure, properties under investigation and solvents and/or salt composition. In addition to the functional form of the equation, the performance of any electrolyte model is based on many factors: the number of adjustable parameters, the accurate description of pure water (solvent), the choice of ion specific or salt specific parameters, the approach of parameterization i.e. whether salts /ion parameters are included during optimization and over what experimental data, and the study of various effects, for instance the effect of concentration on dielectric constant. While the majority of electrolyte models consider only salts that fully dissociate [16-19], a substantial minority of the models also consider partial dissociation [20-23]. A large body of work on electrolyte equations of state (EoS) has already been reviewed $[4,24,25]$.

\subsection{Activity coefficients vs equation of state}

For phase equilibrium calculations, the main property that needs to be computed is the chemical potential, which is defined as:

$$
\mu_{i}=\mu_{i}^{r e f}\left(T, P_{0}\right)+R T \ln \frac{f_{i}}{f_{i}^{r e f}}
$$

where the reference state (indicated by an $r e f$ ) is generally taken either as the pure liquid solvent or as the fluid mixture in the ideal gas state at the same pressure and temperature. In the first case, the equation becomes

$$
\mu_{i}=\mu_{i}^{*}\left(T, P^{\sigma}\right)+R T \ln x_{i} \gamma_{i}
$$

where $\gamma_{i}$ is the activity coefficient, which requires the use of a suitable model (e.g. Pitzer, eNRTL [2628], eUNIQUAC [29]). The reference state (here indicated with *) is generally taken, for neutral molecules, at its vapor pressure $\left(P^{\sigma}\right)$, while for ions, infinite dilution in the solvent, which is most often pure water. The drawback of this approach is that no pressure dependence is considered, since the activity coefficient models are generally pressure independent.

In the second case, we have:

$$
\mu_{i}=\mu_{i}^{\#}(T, P, x)+R T \ln \varphi_{i}
$$

where $\varphi_{i}$ is the fugacity coefficient that requires an equation of state (EoS). The reference state (here indicated by \#) is then the fluid mixture taken as an ideal gas at the same temperature $\mathrm{T}$ and pressure $\mathrm{P}$ as the fluid mixture ( $x$ : vector of composition). The logarithm of the fugacity coefficient is obtained using the mole number derivative of the volume-based residual Helmholtz energy [30]:

$$
R T \ln \varphi_{i}=\frac{\partial A^{r e s}(T, V)}{\partial n_{i}}-R T \ln (Z)
$$

where $Z$ is the compressibility factor. The relationship between the two approaches can be obtained using the definition of activity coefficients: 


$$
\gamma_{i}=\frac{\varphi_{i}}{\varphi_{i}{ }^{r e f}}
$$

The models most often used in industry [31] are based on activity coefficients (the most known ones are Pitzer [32], modified e-NRTL [26-28] and e-UNIQUAC [29], as well as MSE [33,34]). In addition to their low pressure limitation, these models rely on adjusting many interaction parameters against the available experimental data. Their predictive capability is therefore very weak. Today, many researchers try to develop electrolyte EoS [4,35,36] which are based on the fugacity coefficient framework. They are able to account for pressure effects and allow combining the emerging statistical thermodynamic models (as the Statistical Associating Fluid Theory- SAFT- EoS based on Wertheim's association theory [37-40]) with electrolyte thermodynamics. As such, they make it possible to describe simultaneously complex molecular interactions as those occurring in bio-systems [41-45], for example, electrolytic effects [46-50]. Yet their capabilities in modeling multi-solvent electrolyte systems are limited [33].

\subsection{Available equations of state (EoS) for mixed-solvent electrolytes}

A good review on electrolyte thermodynamics was published by Loehe and Donohue [51], that included models from 1985 to 1997. Another review by Prausnitz [52] presented a brief account of electrolyte thermodynamics including their applicability in the biotechnology industry. A short review by Pinsky and Takano [53] presents some local composition models emphasizing computational details of activity coefficient models. Lin et al. [35] and Tan et al. [36] presented an account on electrolyte equations of state in conjunction with SAFT and electrolytic theories. In addition to these, Michelsen and Mollerup [30] presented a thorough discussion including the derivation of the Debye-Hückel theory and the theories of dipolar ions.

An extensive review of electrolyte EoSs is already presented by Kontogeorgis [4] and Maribo-Mogensen [54], an extension of those reviews including some newer ones is presented here in table 1 . This table presents the models with a mention of their parent/base equation, the type of electrolyte term employed, whether or not the Born term is used, and some indications regarding the functional form of the dielectric constant needed in the electrolyte terms (i.e. density-dependent -indicated with $V$; solvent concentrationdependent -indicated with $n$; salt concentration-dependent - indicated with $i$ ). It also states, for SAFTtype models, whether ion-ion or ion-solvent association is considered.

The table shows that the models differ on the incorporation of short-range [29,55-57] and long-range forces as Debye-Hückel (DH) or mean spherical approximation(MSA) $[58,59]$. These models can also differ on the basis of their treatment of salt dissociation: some make use of ion-specific parameters [49], others utilize salt specific parameters[22]. Still others consider a combination of both salt and ion parameters $[23,60]$.

Some versions of CPA $[35,54,61]$ and SAFT $[25,62-68]$ have been extended to model mixed-solvent electrolyte systems. However, most of them rely on fitting salt specific binary parameters which compromises with the predictive capability of the model [69].

Table 1 Review of electrolyte equations of state. This review presents an extension of the earlier reviews[4]. The electrolyte models are classified on the basis of their parent EoS model and their model for electrolytes, whether they use a term to describe solvation or not, whether they describe ion as associating species or not and on the functional form of the dielectric constant.

\begin{tabular}{|c|c|c|c|c|c|c|}
\hline Model & Reference & $\begin{array}{l}\text { Parent } \\
\text { base } \\
\text { model }\end{array}$ & $\begin{array}{c}\text { Electrolyte } \\
\text { model }\end{array}$ & $\begin{array}{l}\text { use of } \\
\text { Born } \\
\text { term }\end{array}$ & $\begin{array}{l}\text { Dielectric } \\
\text { constant }\end{array}$ & $\begin{array}{c}\text { Ion } \\
\text { associatio } \\
\mathrm{n}\end{array}$ \\
\hline \multirow[t]{2}{*}{$\begin{array}{c}\text { e-SRK } \\
\text { (ion specific) }\end{array}$} & Lin et al. [35] & SRK & $\begin{array}{c}\text { nRP-MSA } \\
\text { and DH }\end{array}$ & Born & $\mathrm{T}, \mathrm{V}$ & - \\
\hline & Simon et al.[7o] & SRK & $\mathrm{DH}$ & Born & $\mathrm{T}, \mathrm{V}, \mathrm{i}$ & - \\
\hline e-(VL+DH) (ion & Zerres et al.[71] & Van Laar & $\mathrm{DH}$ & - & $\mathrm{T}, \mathrm{V}\left[\mathrm{72}^{2}\right]$ & - \\
\hline
\end{tabular}




\begin{tabular}{|c|c|c|c|c|c|c|}
\hline specific) & & & & & & \\
\hline $\begin{array}{l}\text { e-PR (MSA) (ion } \\
\text { specific) }\end{array}$ & Myers et al.[22] & PR & RP-MSA & Born & $\mathrm{T}, \mathrm{V}$ & - \\
\hline \multirow[t]{6}{*}{ e-CPA (ion specific) } & Inchekel et al.[73] & CPA & nRP-MSA & Born & $\mathrm{T}, \mathrm{V}$ & - \\
\hline & Inchekel et al. [73] & CPA & $\begin{array}{l}\text { SR2, nRP- } \\
\text { MSA }\end{array}$ & Born & $\mathrm{T}, \mathrm{V}, \mathrm{i}$ & - \\
\hline & Carvallho et al. [74] & CPA & DH & - & $\mathrm{T}$ & - \\
\hline & Schlaikjer et al. [75] & CPA & $\mathrm{DH}$ & Born & $\mathrm{T}, \mathrm{V}, \mathrm{i}$ & - \\
\hline & Mogensen et al. [54] & CPA & $\mathrm{DH}$ & Born & $\mathrm{T}, \mathrm{V}, \mathrm{i}$ & - \\
\hline & Courtial et al [61] & $\mathrm{CPA}$ & nRP-MSA & Born & $\mathrm{T}, \mathrm{V}, \mathrm{i}$ & \\
\hline e-BH & Harvey et al. [18] & $\mathrm{BH}$ & nRP-MSA & Born & $\mathrm{T}, \mathrm{V}$ & - \\
\hline e-PT (salt specific) & Zuo/Guo [76] & $\mathrm{PT}$ & $\mathrm{DH}$ & - & $\mathrm{T}$ & - \\
\hline \multicolumn{7}{|c|}{ SAFT based models } \\
\hline \multirow[t]{18}{*}{ e-SAFT (ion specific) } & Galindo et al. [77] & SAFT-VR & RP-MSA & - & $\mathrm{T}$ & \\
\hline & Patel et al. [66] & SAFT-VR & RP-MSA & - & $\mathrm{T}$ & $\mathrm{I}-\mathrm{S}$ \\
\hline & Schreckenberg et al.[68] & SAFT-VR & nRP-MSA & Born & $\mathrm{T}, \mathrm{V}[72]$ & $\begin{array}{l}\text { I-I } \\
\text { I-S }\end{array}$ \\
\hline & Eriksen et al.[78] & $\begin{array}{l}\text { SAFT-VR } \\
\text { - Mie }\end{array}$ & nRP-MSA & Born & $\mathrm{T}, \mathrm{V}$ & $\begin{array}{l}\text { I-I } \\
\text { I-S }\end{array}$ \\
\hline & Monir et al.[64] & SAFT-VR & MSA & - & $\mathrm{T}$ & $\mathrm{I}-\mathrm{S}$ \\
\hline & Das et al[65].[25] & $\begin{array}{c}\text { SAFT- } \\
\text { VR+DE }\end{array}$ & nP-MSA & - & $\mathrm{T}, \mathrm{V}[79]$ & $\begin{array}{l}\mathrm{I}-\mathrm{I} \\
\mathrm{I}-\mathrm{S}\end{array}$ \\
\hline & $\begin{array}{l}\text { Sadowski et al. } \\
{[49,50,56,80-82]}\end{array}$ & PC-SAFT & $\mathrm{DH}$ & - & $\mathrm{T}$ & I-S \\
\hline & Held et al [46] & PC-SAFT & $\mathrm{DH}$ & - & & \\
\hline & Shadloo et al.[62] & PC-SAFT & $\mathrm{DH}$ & - & $\mathrm{T}$ & \\
\hline & Doozandeh et al. [63] & SAFT & RP-MSA & - & $\mathrm{T}$ & \\
\hline & Liu et al. [83] & LJ-SAFT & $\begin{array}{l}\text { nPMSA } \\
\text { (LDE) }\end{array}$ & & $\mathrm{T}, \mathrm{i}$ & $\begin{array}{l}\mathrm{I}-\mathrm{I} \\
\mathrm{I}-\mathrm{S}\end{array}$ \\
\hline & Radosz et al. [23,84] & SAFT1 & RP-MSA & - & $\mathrm{T}$ & - \\
\hline & Ji et al. [23] & SAFT1 $_{1}$ & RP-MSA & - & $\mathrm{T}$ & - \\
\hline & Radosz et al.[85-88] & $\mathrm{SAFT}_{2}$ & RP-MSA & - & $\mathrm{T}$ & - \\
\hline & Ji et al.[85-87] & SAFT2 & RP-MSA & - & $\mathrm{T}, \mathrm{V}$ & - \\
\hline & Jiang et al.[67] & SAFT2 & $\begin{array}{c}\text { cMSA } \\
\text { (corrected } \\
\text { MSA) }\end{array}$ & - & $\mathrm{T}, \mathrm{V}$ & - \\
\hline & Lee and Kim [89] & PC-SAFT & MSA & Born & $\mathrm{T}$ & I-I \\
\hline & Rozmus [9o] & $\begin{array}{l}\text { PPC- } \\
\text { SAFT }\end{array}$ & nRP-MSA & Born & $\mathrm{T}, \mathrm{V}, \mathrm{i}[91]$ & $\begin{array}{l}\text { I-I } \\
\text { I-S }\end{array}$ \\
\hline \multirow[t]{7}{*}{ e-SAFT (salt specific) } & $\begin{array}{c}\text { Mohammad et al. } \\
{[48,92,93]}\end{array}$ & PC-SAFT & $\mathrm{DH}$ & - & $\mathrm{T}, \mathrm{V}, \mathrm{i}$ & - \\
\hline & W.Liu et al. [94] & LJ-SAFT & nPMSA & - & $\mathrm{T}$ & - \\
\hline & Z.Liu et al. [95] & LJ-SAFT & nPMSA & - & $\mathrm{T}, \mathrm{V}$ & $\begin{array}{l}\mathrm{I}-\mathrm{I} \\
\mathrm{I}-\mathrm{S} \\
\end{array}$ \\
\hline & Radosz et al. $[23,84]$ & SAFT1 & RP-MSA & - & $\mathrm{T}$ & - \\
\hline & Radosz et al. [85-88] & SAFT2 & RP-MSA & - & $\mathrm{T}$ & - \\
\hline & Herzog Gross et al. [96] & PC-SAFT & nPMSA & & $\mathrm{T}$ & I-S \\
\hline & Najafloo et al. $[97,98]$ & SAFT-HR & RP-MSA & Born & $\mathrm{T}$ & - \\
\hline
\end{tabular}

SRK: Soave-Redlich-Kwong; PR: Peng-Robinson; CPA: Cubic Plus Association; BH: Barker Henderson, PT: Patel-Teja, SAFT-VR+DE: SAFT Variable range +Dipole and electrolyte; MSA: Mean spherical approximation, nPMSA: non-Primitive MSA, RP-MSA: restricted primitive MSA, nRP-MSA: non restricted primitive MSA; MSA(LDE): MSA low density expansion, DH: Debye Huckel

T, V, i : Temperature, Volume, ion concentration; I-I: Ion-Ion, I-S : Ion-solvent

\subsection{Thermodynamic cycle: significance of each term}

Thermodynamic models are often constructed using a thermodynamic cycle, where each transformation, which corresponds to a specific interaction being turned on, brings in an additive contribution to the total Gibbs energy (in the case of activity coefficient models) or Helmholtz energy (in the case of equations of state). In the case of an equation of state, the residual Helmholtz energy at given volume 
and temperature is computed. We can then use as an example the thermodynamic cycle that is proposed by Rozmus [9o]:

$$
\Delta \mathrm{A}^{\text {res }}=\Delta \mathrm{A}^{\mathrm{hc}}+\Delta \mathrm{A}^{\mathrm{disp}}+\Delta \mathrm{A}^{\text {assoc }}+\Delta \mathrm{A}^{\text {polar }}+\Delta \mathrm{A}^{\mathrm{MSA}}+\Delta \mathrm{A}^{\text {Born }}+\Delta \mathrm{A}^{\mathrm{NAHS}}
$$

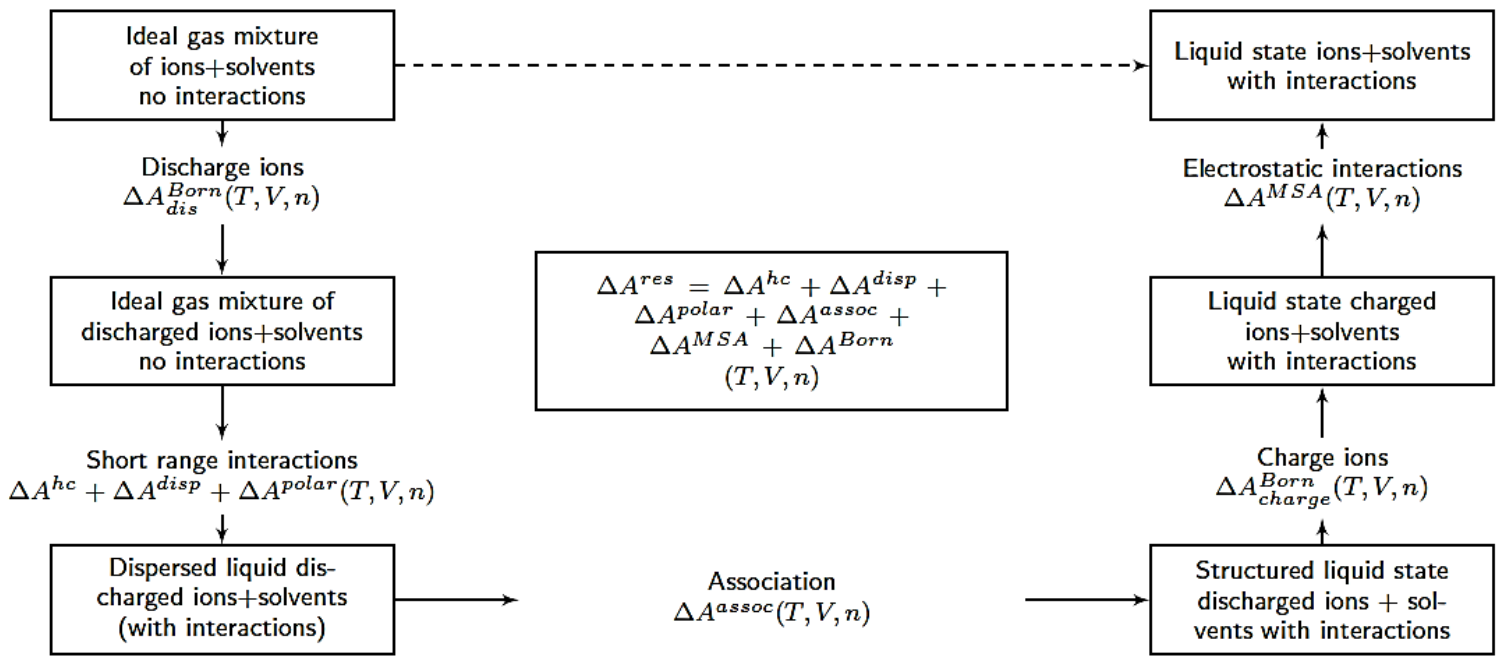

Figure 1 Steps in forming an electrolyte thermodynamic equation of state

The starting point is the mixture containing all species considered, but in its ideal gas state. This means that the species have no volume and no interactions. They only have kinetic energy.

\subsubsection{Discharge}

In a first step, the ions are discharged so as to yield the same mixture but without charge. The energy associated with this transformation is generally described using the Born equation [99] :

$$
\Delta A_{\text {dis }}^{\text {Born }}(T, V, n)=-\frac{N_{A} e^{2}}{4 \pi \varepsilon_{0} R T} \sum_{\text {ions }} \frac{n_{i} Z_{i}^{2}}{\sigma_{i}}
$$

where $\sigma_{i}$ is the solvation diameter of the ion, $Z_{i}$ its charge, $\varepsilon_{0}$ is the permittivity of vacuum, $e$ is the electronic charge and $R$ is the Universal Gas constant.

\subsubsection{Repulsion and dispersion}

In a second step, repulsive and attractive interactions are turned on (the species are given a volume, van der Waals, polar or hydrogen-bonding potentials). This step can be modeled with any equation of state. In fact, electrolyte equations of state have been proposed since the 9o's using cubic equations of state (SRK with Fürst \& Renon [19], Zuo et al. [76], Lin et al. [35], or PR with Myers et al. [22]. More recent works are based on either CPA [35] or one of the SAFT versions (see Table 1).

\subsubsection{The Structure-forming step}

Note that in this second step, the ions, though they remain present throughout the cycle, are considered in the same way as neutral molecules, which means that their only interactions are shortrange repulsion and attraction. No specific structure is created. This is obviously not the case, so the next 
transformation that must be considered is the structure-forming of the ions: water molecules will cluster around the ions to form the so-called "solvation shell". This phenomenon is also called "hydration". Water, a polar molecule, tends to align its negative center around a cation, which forms a hydration shell.

Many molecular simulation studies exhibited this structure-forming phenomenon. As an example, figure 2 shows the radial distribution functions (rdf) in an aqueous $\mathrm{NaCl}$ solution at $1 \mathrm{~mol} / \mathrm{kg}$ and $298.15 \mathrm{~K}$ between the pairs $\mathrm{Na}^{+} / \mathrm{O}$ and $\mathrm{Cl}^{-} / \mathrm{O}$ (where $\mathrm{O}$ is the oxygen atom of the water molecules) obtained from Monte Carlo simulations [10o]. Using an integral oof the rdf, this figure also shows the number of water molecules surrounding each ion, also called the coordination numbers $(\mathrm{CN})$. These coordination numbers show that in the first solvation shell there is approximately the same number of water molecules surrounding both cation $\left(\mathrm{Na}^{+}\right)$and anion $\left(\mathrm{Cl}^{-}\right)$(6-7). The structure of water-ion mixtures is discussed at length in [101].

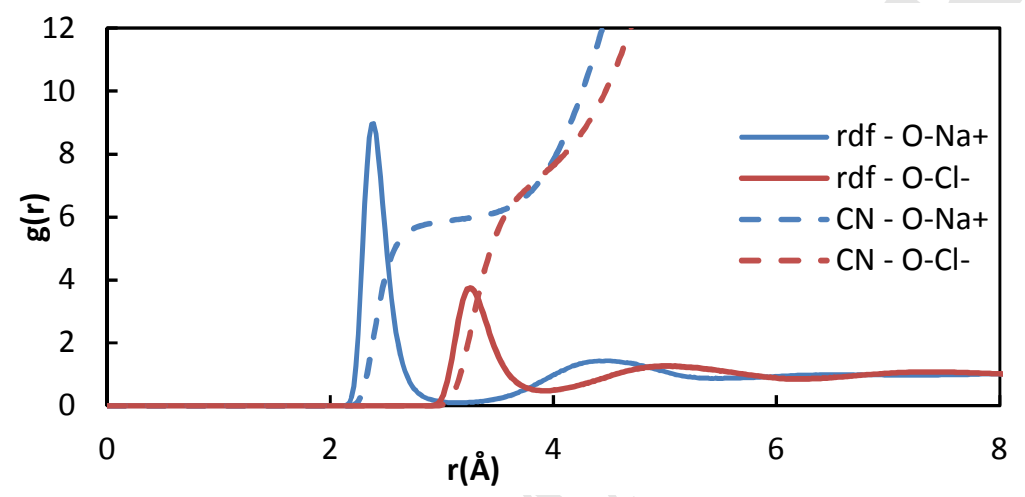

Figure 2 Radial distribution function (rdf) and coordination number $(\mathrm{CN})$ between $\mathrm{Na}^{+} / \mathrm{O}$ pairs and $\mathrm{Cl}^{-} / \mathrm{O}$ pairs obtained from Monte Carlo simulations [10o]

Fürst \& Renon [19] used a specific "short range" term to describe the solvation phenomenon, but Inchekel [73] showed some inconsistencies with this term and proposed, as many others, to use the Born term instead. Yet, as we demonstrate here, the objective of the Born term is different from describing the structuring effect of ions. Several other authors $[41,47,77,92,93]$ adjust a binary interaction parameter for the dispersion term to model this phenomenon. Several authors (e.g., Rozmus [9o] and Herzog et al. [96]) use the Wertheim association term for describing this phenomenon: it allows describing the disruption of the water-water hydrogen bonds and the formation of hydration interactions in the presence of ions. This choice is also made in the present work. The short-range nature and the strong hydration interactions make the use of the SAFT association term a natural choice to model this phenomenon. The complexity comes in the selection of the number of sites on each ion. As is discussed below, we have compared two different hydration numbers: one from Bockris and Reddy [102] and other from molecular simulations to find the most suitable hydration numbers.

\subsubsection{Electrolyte terms}

The next two transformations (figure 1) are related to the presence of an electric charge on the ions: the charging effect of each single ion, and the energy related to the long-range ion-ion interactions. These two phenomena are related, and the non-primitive MSA theories [25, 96] consider them explicitly. However, they are complex and rather not easy to use in process simulation context. The other existing models propose a sum of the two effects. 
1. The Born term is used again to describe the energy related to the turning "on" of a point charge on each individual ion. It is identical to equation (7), except for the sign and the fact that now the actual liquid solution dielectric constant is used

$$
\Delta A_{\text {charge }}^{\text {Born }}(T, V, n)=\frac{N_{A} e^{2}}{4 \pi \varepsilon_{0} \varepsilon R T} \sum_{\text {ions }} \frac{n_{i} Z_{i}^{2}}{\sigma_{i}}
$$

This makes that the global Born contribution become:

$$
\frac{A^{\text {Born }}}{R T}=-\frac{N_{A} e^{2}}{4 \pi \varepsilon_{0} R T}\left(1-\frac{1}{\varepsilon}\right) \sum_{i o n s} \frac{n_{i} Z_{i}^{2}}{\sigma_{i}}
$$

2. Either the Debye-Hückel (DH) [58] or Mean Spherical Approximation (MSA) [103] term is employed to describe ion-ion long-range interactions.

The long-range MSA ionic interaction theories are developed assuming ions to be point charges in a solvent described as a continuum through its dielectric constant. These theories are called "primitive models" (PM). In case of restricted primitive models the ions are treated as having identical (averaged) non-zero diameters, which allows an explicit solution of the so-called screening factor. In non-restricted PM approaches the ions are treated as having different diameters leading to an implicit model with an iterative solution[4]. The MSA theory is based on the perturbation of polar fluids where the reference system is in the Percus-Yevick approximation using the Ornstein-Zernike equation as a specific closure.

According to some findings, it appears that MSA theory has an edge over DH theory. Galindo et al. [77] compared the MSA and DH theories for describing short-range interactions and reported that at a higher salt concentration of $\mathrm{NaCl}$, densities were more accurately represented by MSA than by DH. However, for the representation of a vapor, the performance was nearly the same. A Taylor series expansion and the comparison of the mathematical form of both these theories by Lin et al. [104] showed that there are very little differences when assuming the same ion diameters. A recent comparison made by Maribo-Mogensen et al. [24] showed that the two theories gave similar results, when compared numerically in terms of screening length.

Our choice in the applications below is based on the non-restricted primitive approach. It has been recognized by many authors $[105,106]$ as a good representation of the physical phenomenon.

\subsection{Some thoughts and arguments related to the choices made in this work}

\subsubsection{What is solvation?}

The term solvation, also called hydration in the case of water, is used with different meanings in the literature: either it means the phenomenon related to the forming of a specific structure around an ion or that of insertion of an ion from the ideal gas to the pure solvent. From the above discussion, it is clear that the second definition, which is better defined from a theoretical point of view, is, in fact, a combination of several elementary transformations: the discharge, the cavity formation (repulsive contribution), the charging process, and the structure-forming effect around water.

The Gibbs energy of hydration from the ideal gas is rather easy to compute using the equation of state (see also Schreckenberg et al. [68]): 
$\Delta G_{s, \text { ion }}=G_{s, \text { ion }}{ }^{\infty}-G_{s, \text { ion }}{ }^{i g}(T, V)=R T \ln \left(\varphi_{\text {ion }}^{\infty} \frac{P_{s}^{\sigma}}{R T \rho_{\text {solvent }}}\right)$

The values can then be compared to experimental values, as for example those given in ref. [107].

In PC-SAFT the final Helmholtz energy is the sum of various contributions such as dispersion (attraction between molecule), hard-sphere (repulsion between molecules), chain (covalent bond energy between molecules), association (hydrogen bonding energy between two associating molecules) polar (interaction energy between polar molecules), MSA (ion-ion long-range interactions) and Born (so-called solvation energy). While calculating the fugacity coefficient as in equation (10) we use the net sum of all these interactions. A look at these individual terms shows the relative contribution of each phenomenon in the computation of the Gibbs energy of hydration:

$$
\begin{aligned}
\frac{\Delta G_{s, \text { ion }}}{R T}= & \left.\frac{\partial A^{\text {res }}(T, V)}{\partial n_{\text {ion }}}\right)^{h c}+\left(\frac{\partial A^{\text {res }}(T, V)}{\partial n_{\text {ion }}}\right)^{\text {dispersion }} \\
& +\left(\frac{\partial A^{\text {res }}(T, V)}{\partial n_{\text {ion }}}\right)^{\text {chain }}+\left(\frac{\partial A^{\text {res }}(T, V)}{\partial n_{\text {ion }}}\right)^{\text {association }} \\
& +\left(\frac{\partial A^{\text {res }}(T, V)}{\partial n_{\text {ion }}}\right)^{\text {polar }}+\left(\frac{\partial A^{\text {res }}(T, V)}{\partial n_{\text {ion }}}\right)^{M S A} \\
& +\left(\frac{\partial A^{\text {res }}(T, V)}{\partial n_{\text {ion }}}\right)^{\text {Born }}-\ln \left(\frac{P_{s}^{\sigma}}{R T \rho_{\text {solvent }}}\right)
\end{aligned}
$$

Figure 3 shows the numerical values for each of these terms at infinite dilution (the condition used for computing Gibbs energy of hydration). The value of $\frac{P_{s}^{\sigma}}{R T \rho_{\text {solvent }}}$ is provided by experiment (eg. 0.2334 at $298.15 \mathrm{~K}$ ). This term (called $\mathrm{Z}$ in figure 3) is clearly insignificant for the Gibbs energy of solvation. The figure shows that the contribution of the Born term is the largest in absolute value (between 450 and $200 \mathrm{~kJ} / \mathrm{mol}$ ). The hard chain term reflects the contribution of cavity formation and the association the structure-forming of water molecules around the ions. The other contributions are absent or negligible in infinite dilution conditions. This validates the argument that the Born contribution is essential for calculating Gibbs energy of solvation $\left(\Delta G_{s}\right)$ as already pointed out by $[68,78]$. The calculations are made using the final parameters that are used in this work (set 1 below in table 7 ).

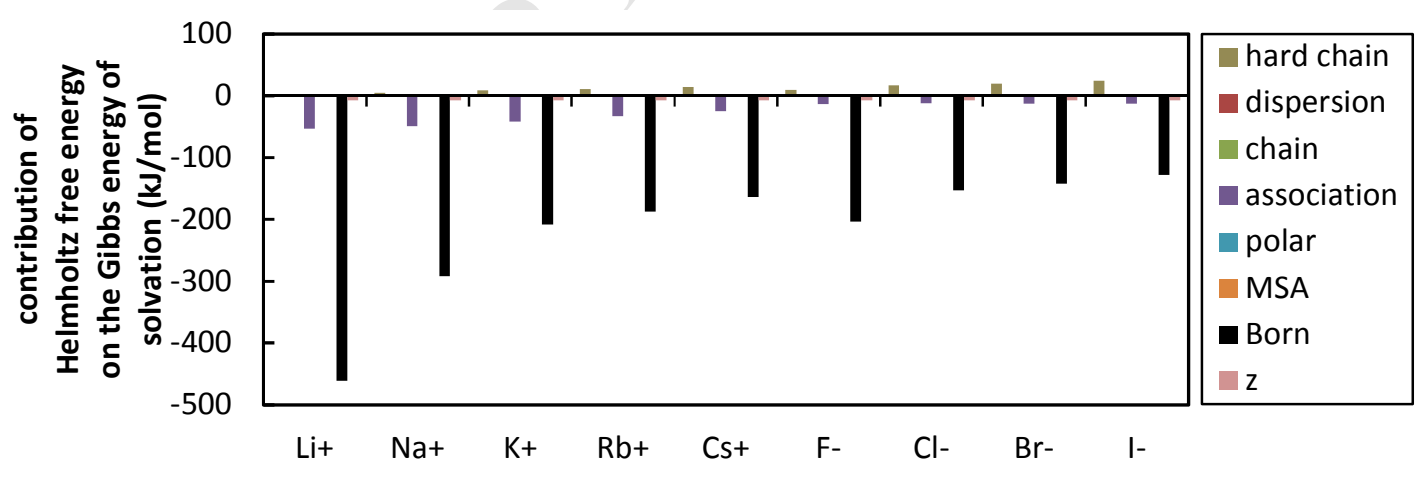

Figure 3 Contribution of Helmholtz free energy $\frac{\partial A}{\partial n_{i}}{ }^{\text {res }}$ (Y-axis) for each term of PC-SAFT and for each ion at infinite dilution. 


\subsubsection{Should the dielectric constant be salt-composition dependent?}

Both the primitive MSA and the Born terms of the ePC-SAFT model require the dielectric constant as an input. For pure compounds, the data for the dielectric constant is abundantly available and hence several correlations exist[108][30] as a function of temperatureand sometimes density or pressure to compute their dielectric constant. In our work, we utilize the correlation proposed by Schreckenberg [68].

Yet, it has been shown experimentally that the dielectric constant is affected by salt concentration $[109,110]$. The dielectric constant of electrolyte mixtures is obtained using an experimental method known as dielectric relaxation spectroscopy. This data includes the contribution of all frequencies and electric conductivity. The dielectric constant is then calculated by extrapolating the frequency dependent permittivity to zero frequency [111]. While there is always some level of ambiguity associated to the experimental dielectric constant due to the choice of the relaxation model, the bigger problem is due to the fact that the experimental dielectric constants contain both equilibrium and non-equilibrium contribution. The non-equilibrium contribution is what is known as kinetic depolarization. Only the equilibrium contributions is required in electrolyte EoS.

Most authors of industrial electrolyte models consider that the dielectric constant to be used in the MSA and Born terms is independent of the salt concentration [4]. The reason for this is that the Born and MSA terms are developed in conditions of infinite dilution. They provide a corrective energy related to the charging of one ion or the ion-ion interactions. Yet, when considering the thermodynamic cycle that is presented above, it is clear that all steps bear on a system that has identical composition, temperature, and volume. Only the interactions between the species vary. Hence, when the charge is brought on the ions (charging Born term), or when the charge-charge ionic interactions are considered (MSA or DH term), the solution is not that of the infinite dilution reference state, but in terms of composition equal to that of the actual solution. This is why some authors $[73,90]$ suggest using the salt concentration-dependent dielectric constant. Recently, Ignat and Shilov [110] used a concentration-dependent dielectric constant of several alkali halide salts to calculate their activity in an aqueous solution without any parameter adjustment which showed a semi-quantitative agreement to experimental data.

Another argument can be found in the fact that because applications generally deal with high salinities, the Born and MSA terms with infinite dilution as reference state are far beyond their application range. Hence, additional corrections would be needed anyhow. In fact, Maribo-Mogensen [109,112] has shown that the use of such a dependency provides a non-negligible improvement on the behavior of the compositional derivative of the Helmholtz energy.

An interesting method for evaluating the effect of each term on the Mean Ionic Activity Coefficient (MIAC) eq. 25-26 was provided by Inchekel et al. [73]. The combination of equations (3) and (4) allow writing the mean ionic activity coefficient as follows:

The ionic activity coefficient is defined as the ratio of fugacities in the mixture and in the reference state, generally pure water.

$$
\begin{gathered}
R T \ln \left(\gamma_{\text {ion }}\right)=R T \ln \left(\frac{\varphi_{\text {ion }}}{\varphi_{\text {ion }}^{*}}\right)=R T \ln \left(\varphi_{\text {ion }}\right)-R T \ln \left(\varphi_{\text {ion }}^{*}\right) \\
=\left(\sum \frac{\partial A^{X}}{\partial n_{\text {ion }}}-\sum \frac{\partial A^{* X}}{\partial n_{\text {ion }}}\right)-R T \ln \left(\frac{Z}{Z^{*}}\right)=\sum\left(\frac{\partial A^{X}}{\partial n_{\text {ion }}}-\frac{\partial A^{* X}}{\partial n_{\text {ion }}}\right)-R T \ln \left(\frac{Z}{Z^{*}}\right)
\end{gathered}
$$

Where $\mathrm{X}=$ all contribution from the EoS. It is then possible to plot the contribution of each of these terms to the global property. Figure 4 shows such a plot, with the ePPC-SAFT model discussed in section 3 (i.e; including a composition-dependent dielectric constant). 


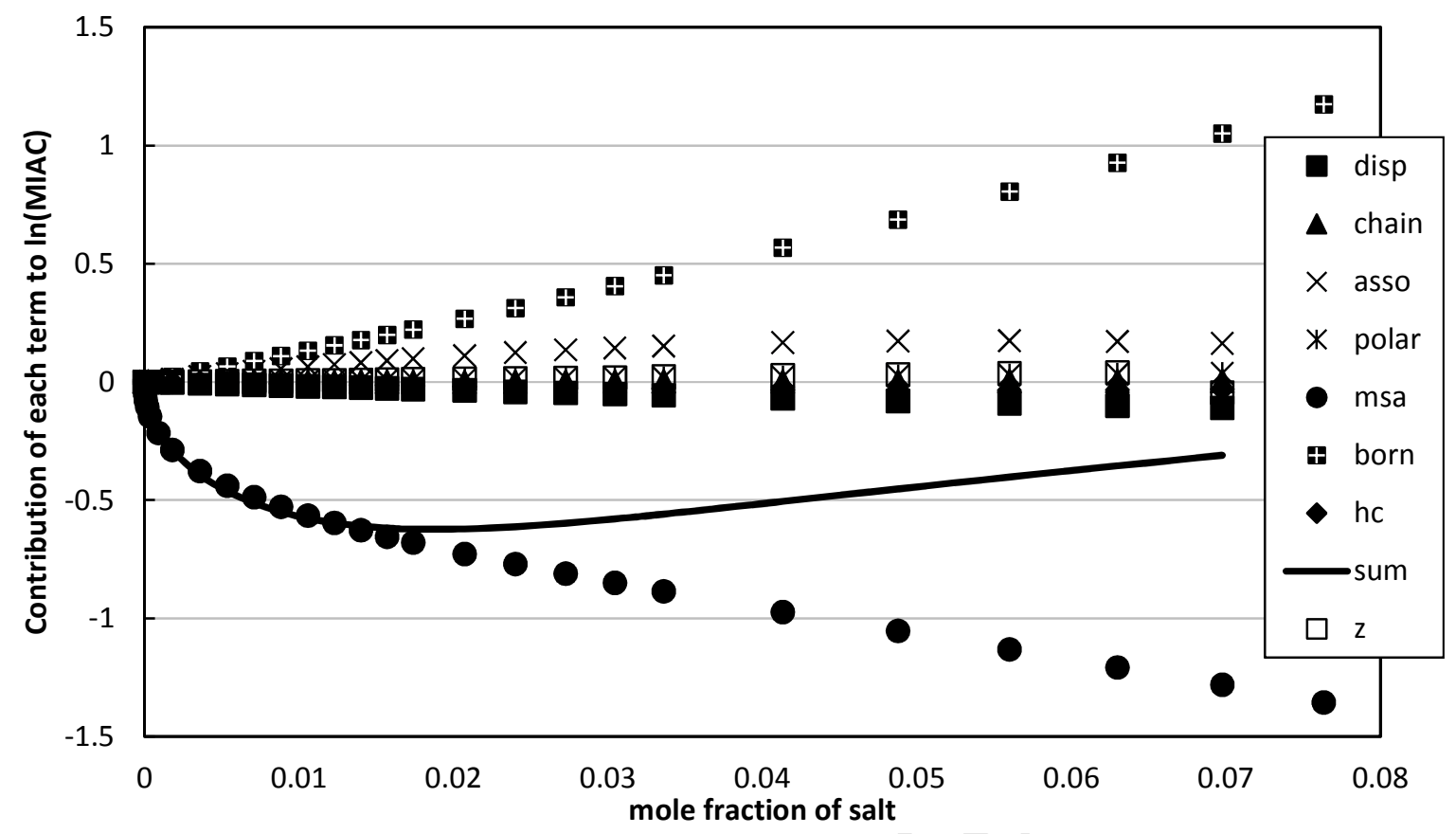

Figure 4 Effect of the various terms on the logarithm of the mean ionic activity coefficient (MIAC) for $\mathrm{NaCl}$ at $298.15 \mathrm{~K}$. The model used is that presented in section 3 along with the parameters presented in table 6.

In the same way as already pointed out by Inchekel et al. [73], the figure shows clearly that the most significant contributions to the MIAC are the Born and the MSA terms, which need to balance out in order to obtain the well-known curved behavior with a minimum close to 1 molal (see curve "sum"). The same plot could be shown with a model not taking into account the salt dependence of the dielectric constant. In this case, no significant change is expected from the non-electrolyte terms. The behavior of the MSA term is essentially identical, but the Born contribution would necessarily be zero. This is because:

$$
\left(\frac{\partial A}{\partial n_{i}}-\frac{\partial A^{*}}{\partial n_{i}}\right)^{B o r n}=\frac{N_{A} e^{2}}{4 \pi \varepsilon_{0}}\left[\frac{Z_{i}^{2}}{\sigma_{i}}\left(\frac{1}{\varepsilon}-\frac{1}{\varepsilon^{*}}\right)-\left(\sum_{j=i o n s} \frac{n_{j} Z_{j}^{2}}{\sigma_{j}}\right) \frac{1}{\varepsilon^{2}}\left(\frac{\partial \varepsilon}{\partial n_{i}}\right)_{V, T, n_{i} \neq i}\right]
$$

Where the dielectric constant $\varepsilon=\varepsilon^{*}$ and its derivative with mole fraction of ion is zero. As a consequence, another contribution should balance out with the large negative value of MSA (which is necessarily so because it doesn't contain any adjustable parameter). Most often, a large dispersive energy parameter $\left(k_{i j}\right)$ is used such that the dispersive term is used for that purpose. Yet, an analysis of the physical significance of the above representation puts into question this choice: it can be considered that the ionic activity coefficient describes whether the ions 'likes' being in salt water better than in pure water, or not. Indeed, the fugacity, or 'escaping tendency' of the ion is proportional with the activity coefficient. When the activity coefficient is larger than 1 (positive logarithm), the ion prefers escaping from the salty water: it prefers pure water (the reference state). When, on the contrary, the activity coefficient is smaller than 1 (negative logarithm), the ions prefer to be in salty water.

Now, if we consider the terms individually, we see that the MSA term, which describes the long-range electrostatic interactions between ions, always has a negative contribution. This indicates that the corresponding potential makes the ions 'like better' being surrounded by other ions: this is directly related to the decrease in screening length as discussed by Maribo-Mogensen [24]: the presence of other ions will tend to neutralize the strong local charge that is brought by the individual ion. Hence, the local electrostatic field strength will be reduced. 
On the other hand, the observed positive contribution of the Born term can be explained by the fact that the presence of salts reduces the dielectric constant. The energy needed to charge an ion from the vacuum is directly related to this property: the larger the dielectric constant, the lower the energy needed (the dielectric continuum makes it more comfortable for the ions). Hence, from that point of view, the ions prefer being in pure water rather than in salty water.

The other terms have a much smaller impact on the 'ionic happiness'. We see that the association (using our frame stating that association describes the forming of a hydration shell) tends to make that ions dislike salty water. This is because the water hydrogen bond network is disrupted as a consequence of their presence. The hard chain contribution is negative, because mixing spheres of different diameters creates entropy, thus increasing the stability of the mixture.

\section{Proposed model}

\subsection{The SAFT equation of state}

Physically, the Statistical Associating Fluid Theory (SAFT) is based on statistical perturbation theory where perturbation terms are used to correct the Helmholtz energy of a reference system.

This work propose the use of the GC-ePPC-SAFT electrolyte model by Rozmus et al. [90,113] as a basis. It is based on PC-SAFT [56] and extended to polar molecules [114-116] of Jog and Chapman theory for multipolar molecules [117] $\left(A^{\text {polar }}\right)$. The group contribution method [118] is not used in this paper. The dispersive contribution is calculated by applying perturbation to the reference fluid (which for PC-SAFT is a hard chain) based on a Lennard-Jones type pair-potential. These hard spheres are assumed to have association sites on their surface which makes it possible to calculate the Helmholtz energy contribution due to association $\left(A^{a s s o c}\right)$. This can also be used to calculate chain contributions by considering an infinite association strength. The electrolyte terms $A^{M S A}$ and $A^{B o r n}$ are also incorporated along with these terms as proposed by Inchekel et al. [73]. We will also use in this paper the correction for non-additivity of the hard sphere diameters (NAHS standing for Non-Additive Hard Sphere) that was proposed by Trinh et al. $[119,120]$. The representative equation is given in eqn. 15 .

$$
\mathrm{A}^{\mathrm{res}}=\left(\mathrm{mA}^{\mathrm{hs}}+\mathrm{A}^{\text {chain }}\right)+\mathrm{A}^{\mathrm{disp}}+\mathrm{A}^{\text {assoc }}+\mathrm{A}^{\text {polar }}+\mathrm{A}^{\mathrm{NAHS}}+\mathrm{A}^{\mathrm{MSA}}+\mathrm{A}^{\mathrm{Born}}
$$

The detailed mathematical expressions of the individual terms can be found in the original papers and are omitted here. Further details related to GC-PPC-SAFT can be obtained in refs [114-116,121-127,127]. Parameters for the GC-PPC-SAFT have been determined in previous papers while the parameters that are used in this work are presented here in table 3-5.

\subsection{Specificities related to the GC-ePPC-SAFT model}

The model used in this work is almost identical to that already discussed by Rozmus et al. [9o]. Yet, since our objective was the treatment of mixed solvents, some modifications have been introduced.

\subsubsection{The electrolyte terms}

The terms that take into account the presence of charged species (MSA and Born) have not been modified [9o]. Yet, the functional form of the dielectric constant is revisited. In the current work, the values of the dielectric constants for pure solvents are calculated using correlations eq. 16 developed by Schreckenberg [68]. The parameters are recalled in table 2 and for mixtures the mixing rule is given in eqn. 17 . 
Table 2. Correlations for calculating dielectric constants of the pure solvent.

\begin{tabular}{|l|c|c|c|c|}
\hline Component & MW & $d_{v}\left(\frac{d m^{3}}{m o l}\right)$ & $d_{T}(\mathrm{~K})$ & \%AAD \\
\hline Water & 18.02 & 0.3777 & 1403.0 & 0.97 \\
\hline Methanol & 32.05 & 0.5484 & 1011.0 & 0.86 \\
\hline Ethanol & 46.07 & 0.9480 & 732.1 & 1.44 \\
\hline
\end{tabular}

$$
\begin{gathered}
\varepsilon_{s}=1+\frac{\sum_{i}^{n} N}{V_{\text {system }}} d_{v}\left(\frac{d_{T}}{T}-1\right) \\
d_{v}=\frac{\sum_{i}^{\text {solvents }} n_{i} d_{v, i}}{\sum_{i}^{\text {solvents }} n_{i}} \quad \text { and } \quad d_{T}=\frac{\sum_{i}^{\text {solvents }} n_{i} d_{T, i}}{\sum_{i}^{\text {solvents }} n_{i}}
\end{gathered}
$$

In order to take into account the effect of ionic species on the dielectric constant, Pottel's [128] model is used: (eq. 18-19).

$$
\varepsilon-1=\left(\varepsilon_{s}-1\right) \frac{1-\xi_{3}^{\prime \prime}}{1+\xi_{3}^{\prime \prime} / 2}
$$

where $\varepsilon_{S}$ is the dielectric constant of the (mixed) solvent, $\sigma_{i}^{H S}$ is the ionic diameter, $V$ is the volume of the system.

$$
\xi_{3}^{\prime \prime}=\frac{N_{A v} \pi}{6} \sum_{i}^{i o n s} \frac{n_{i}\left(\sigma_{i}^{H S}\right)^{3}}{V}
$$

\subsubsection{The Association term}

In the present approach, and as discussed in the theoretical section above, the association term is used both for describing the solvent-solvent interactions (including mixed solvents), ion-solvent and ionion short-range interactions. The association parameters are interaction parameters. Yet, most often (including in this work), they will be computed from pure component parameters using the so-called CR1 combining rule (Derawi et al. [129]).

$$
\begin{gathered}
\varepsilon^{A_{i} B_{j}}=\left(1-w_{i j}\right)\left(\frac{\varepsilon^{A_{i}}+\varepsilon^{B_{j}}}{2}\right) \\
\kappa^{A_{i} B_{j}}=\left(1-u_{i j}\right) \sqrt{\kappa^{A_{i}} \kappa^{B_{j}}}
\end{gathered}
$$

Where $\varepsilon^{A_{i}}, \varepsilon^{B_{j}}, \kappa^{A_{i}}$ and $\kappa^{B_{j}}$ are attributed to pure components, and $w_{i j}$ and $u_{i j}$ are adjustable interaction parameters that allows regressing the combining rules when needed.

This means that regressing the ionic parameter $\varepsilon^{A_{i}}$, the interaction is equivalent to regress the actual interaction parameter $\varepsilon^{A_{i} B_{j}}$ (when $w_{i j}=0$ ).

\subsubsection{The Non-additive hard sphere diameter term}

The additional term proposed by Trinh et al. [120] is based on the observation that the usual combining rule that is used on the diameters should be corrected with a new parameter, which is called $l_{i j}$ :

$$
d_{i j}=\frac{d_{i}+d_{j}}{2}\left(1-l_{i j}\right)
$$

where the diameter $\mathrm{d}$ is the temperature dependent parameter as defined by Gross \& Sadowski [130] : 


$$
d(T)=\sigma\left[1-\lambda \exp \left(-3 \frac{\varepsilon}{k T}\right)\right]
$$

where $\lambda$ is the sphere softness whose value is usually fixed equal to o.12.

\subsection{Parameters from previous work}

The parameters utilized in the current work are mentioned in tables (3-4). These parameters are taken from the previous work. 
Table 3 Pure component parameters of water used in this work taken from our previous work [131].

\begin{tabular}{|c|c|c|c|c|c|c|c|c|c|c|c|c|c|}
\hline Parameters & $\begin{array}{c}\text { Segment } \\
\text { number }\end{array}$ & $\begin{array}{l}\text { Segment } \\
\text { diameter }\end{array}$ & Tempe & $\begin{array}{l}\text { rature dep } \\
\text { diameter }\end{array}$ & endent & $\begin{array}{c}\text { Dispersion } \\
\text { energy }\end{array}$ & $\begin{array}{c}\text { Association } \\
\text { energy }\end{array}$ & $\begin{array}{c}\text { Association } \\
\text { volume }\end{array}$ & $\begin{array}{c}\text { Association } \\
\text { type }\end{array}$ & $\begin{array}{c}\text { Sphere } \\
\text { Softness* }\end{array}$ & \begin{tabular}{|c} 
Pseudo \\
ionization \\
energy
\end{tabular} & $\begin{array}{c}\text { Dipole } \\
\text { Moment }\end{array}$ & $\begin{array}{l}\text { Dipole } \\
\text { fraction }\end{array}$ \\
\hline \multirow{2}{*}{ Unit and abbreviation } & - & $\AA$ & $\AA$ & - & $\mathrm{K}^{2}$ & $\mathrm{~K}$ & $\mathrm{~K}$ & - & - & - & & $\mathrm{D}$ & - \\
\hline & $\mathrm{m}$ & $\sigma_{\mathrm{w}}$ & $\mathrm{T}_{\mathrm{dep}, 1}$ & $\mathrm{~T}_{\mathrm{dep}, 2}$ & $\mathrm{~T}_{\mathrm{dep}, 3}$ & $\mathrm{E}$ & $\varepsilon^{\mathrm{AB}} / k$ & $\kappa^{\mathrm{AB}}$ & - & $\lambda$ & $\mathrm{J}$ & $\mu$ & \\
\hline $\begin{array}{c}\text { Parameters (current } \\
\text { work) }\end{array}$ & 1.02122 & 2.2423 & 0.51212 & 0.001126 & 9904.13 & 201.747 & 1813 & 0.044394 & $4 \mathrm{C}$ & 0.203 & 13.65 & 1.85 & 0.276 \\
\hline
\end{tabular}

* This parameter (softness of diameter) is fixed as 0.12 in original PC-SAFT model, however it is made adjustable in the present version of GC-PPC-SAFT.

Table 4 Pure component parameters of alkanes and alcohols used in this taken from [132] work.

\begin{tabular}{|c|c|c|c|c|c|c|c|c|c|c|c|}
\hline Parameters & $\begin{array}{c}\text { Segment } \\
\text { number }\end{array}$ & $\begin{array}{l}\text { Segment } \\
\text { diameter }\end{array}$ & $\begin{array}{c}\text { Dispersion } \\
\text { energy }\end{array}$ & $\begin{array}{c}\text { Association } \\
\text { energy }\end{array}$ & $\begin{array}{l}\text { Association } \\
\text { volume }\end{array}$ & $\begin{array}{c}\text { Association } \\
\text { type }^{* *}\end{array}$ & $\begin{array}{c}\text { Pseudo } \\
\text { ionization } \\
\text { energy }\end{array}$ & $\begin{array}{c}\text { Dipole } \\
\text { Moment }\end{array}$ & $\begin{array}{c}\text { Dipole } \\
\text { fraction }\end{array}$ & $\begin{array}{c}\text { Quadrupole } \\
\text { moment }\end{array}$ & $\begin{array}{c}\text { Quadrupole } \\
\text { fraction }\end{array}$ \\
\hline \multirow{2}{*}{$\begin{array}{c}\text { Unit and } \\
\text { abbreviation }\end{array}$} & - & $\AA$ & $\mathrm{K}$ & $\mathrm{K}$ & - & - & $\mathrm{eV}$ & $\mathrm{D}$ & - & $\mathrm{B}$ & \\
\hline & $\mathrm{m}$ & $\sigma_{\mathrm{w}}$ & $\varepsilon / \mathrm{k}$ & $\varepsilon^{\mathrm{AB} / k}$ & $\kappa^{\mathrm{AB}}$ & - & $\mathrm{J}$ & $\mathrm{d}$ & $x_{p}^{d} * m$ & Q & $x_{p}^{Q}$ \\
\hline Methanol & 2.827 & 2.632 & 166.80 & 2069.09 & 0.2373 & $2 \mathrm{~B}$ & 15.55 & 1.7 & 0.35 & - & - \\
\hline Ethanol * & 2.000 & 3.411 & 247.99 & 2143.30 & 0.00885 & $3 \mathrm{~B}$ & 15.85 & 1.83 & 0.5 & - & - \\
\hline Methane & 1.033 & 3.658 & 147.41 & - & - & - & 12.61 & - & - & - & - \\
\hline Ethane & 1.636 & 3.509 & 189.00 & - & - & $8-$ & 11.52 & - & - & - & - \\
\hline Carbon dioxide & 1.846 & 2.984 & 139.97 & 449.71 & 0.0946 & $2 \mathrm{~B}$ & 13.78 & - & - & 4.3 & 0.5268 \\
\hline Hydrogen Sulfide & 1.302 & 3.416 & 225.05 & 449.71 & 0.0947 & $3 \mathrm{~B}$ & & 0 & 0 & - & - \\
\hline
\end{tabular}

* Ethanol is computed from group contribution as discussed in [133]

** according to the nomenclature [134] 


\section{Ion parameterization procedure}

The model used in this work is almost identical to that already discussed by Rozmus et al. [9o] Although the results presented by Rozmus et al. [90] were of good accuracy, densities of alkali halides were not very well represented at low salinities. This is why the water parameters have been updated. It has also been pointed by several authors that the underlying model for pure solvents must be accurate for calculating their liquid densities $[65,68]$. It is thus important to re-parameterize the ions and see the performance of the new model for liquid densities.

The data used for the regression is presented in table 8. Mean Ionic Activity Coefficient (MIAC) eq. 24 and solution densities $(\rho)$ converted to Apparent Molar Volume (AMV) using eq. 25 were used for parameterization. Their detailed description can be obtained from Rozmus et al. [90].

\section{Mean Ionic Activity Coefficients (MIAC)}

The mean ionic activity coefficient (MIAC) represented by $\gamma_{i}$ is most commonly used to describe the electrolyte solution behaviour. It is calculated directly from the fugacity coefficient and is given as.

$$
\gamma_{i, m}=\frac{\varphi_{i}\left(T, P, x_{i}\right)}{\varphi_{i}^{\infty}\left(T, P, x_{i} \rightarrow 0\right)} x_{w}
$$

where, $\varphi_{i}$ represents the fugacity coefficient of component, $\varphi_{i}^{\infty}$ represents the infinite dilution fugacity coefficient, $x_{w}$ represents the mole fraction of water and $\gamma_{i, m}$ is thus the activity coefficient in which ' $m$ ' stand for molal basis.

The Mean Ionic Activity Coefficient (MIAC) is given by:

$$
\gamma_{ \pm}=\left(\gamma_{+}^{v_{+}} \gamma_{-}^{v_{-}}\right)^{1 /\left(v_{+}+v_{-}\right)}
$$

where the subscripts + and - represents the cation and anion respectively. $v_{+}$and $v_{-}$are the stoichiometric coefficients (on a full dissociation basis).

\section{Apparent Molar Volume}

The apparent molar volume (AMV) of ions is defined is given as:

$$
v_{ \pm}=\frac{v-x_{w} v_{w}}{\left(x_{+}+x_{-}\right)}
$$

where $v$ and $v_{w}$ are the molar volumes of the solution and of pure water respectively, and $x_{+}$and $x_{-}$ are the mole fractions of the cation and the anion. It is impossible to differentiate the contribution of separate ions and hence a representation of \pm is used to denote the overall AMV for the solution containing ions (anions and cations). The AMV is actually the change in the volume of the solution when salts are added into it and hence can be viewed as partial molar volume for electrolyte solutions.

The parameters that can possibly be worked on, are as follows:

- The ionic diameter sigma $(\sigma)$ : there are in fact three: one in the hard sphere term, one in the MSA term and one in the Born term. Rozmus used a single diameter for all contributions of the SAFT EoS, equal to the Pauling diameters. However, it can be argued that the diameters to be used for the MSA term $[107,135,136]$ are not the same as the hard sphere diameter to be used for the repulsive contribution. This is why in this work we kept the Pauling diameter for the hard sphere term but regressed the MSA diameter for each ion. In order to reduce the number of parameters per ion, the diameter for the Born term was taken equal to the Pauling diameter.

- The dispersive energy: while many authors use this parameter to describe the short-range interactions, we propose, as discussed above, to use the association term to describe these short- 
range interactions. Using both dispersive and association at once would yield too many parameters so that we follow Rozmus's suggestion to consider the ionic dispersive energy to be zero.

- The Wertheim association requires two site-site interaction parameters (an energy, $\varepsilon^{A_{i}}$, and a volume, $\kappa^{A_{i}}$.) in addition to the choice of a number of association sites, $N_{s}$. In the same way as proposed by Rozmus, we consider the association volume equal to that of water $=0.044394$. The association energy is regressed individually for each ion. In literature, various authors have used different $N_{s}$, shown in table 6 , the choice can vary widely between results from molecular dynamics calculations or experimental data (IR, spectroscopy).

Table 5. Number of association sites $\left(\mathrm{N}_{\mathrm{s}}\right)$ for ions in different electrolyte models and as calculated using molecular simulation for water- $\mathrm{NaCl}$ system at $298.15 \mathrm{~K}$

\begin{tabular}{|c|c|c|c|c|c|c|c|c|c|}
\hline \multirow[b]{2}{*}{ Ion } & \multirow[b]{2}{*}{$\begin{array}{c}\text { ePC- } \\
\text { SAFT by } \\
\text { Herzog et } \\
\text { al. [96] }\end{array}$} & \multirow[b]{2}{*}{$\begin{array}{l}\text { PREoS(Born } \\
\text { ) by Wu and } \\
\text { Praunitz[137] }\end{array}$} & \multicolumn{7}{|c|}{ Number of association sites $N_{S}$} \\
\hline & & & $\begin{array}{l}\text { ePC- } \\
\text { SAFT } \\
\text { by Lee } \\
\text { and } \\
\text { Kim } \\
{[138]}\end{array}$ & $\begin{array}{c}\text { eSAFT-LJ } \\
\text { by Z Liu. } \\
\text { [83] }\end{array}$ & $\begin{array}{l}\text { eEoS by } \\
\text { Y Liu, et } \\
\text { al.[139] }\end{array}$ & $\begin{array}{c}\text { ePPC- } \\
\text { SAFT } \\
\text { Rozmus et } \\
\text { al [9o] }\end{array}$ & $\begin{array}{c}\text { Molecular } \\
\text { simulations } \\
\text { (average over } \\
\text { salt molality 1-5 } \\
\text { m) }\end{array}$ & $\begin{array}{c}\text { Bockris et } \\
a l .[101]\end{array}$ & $\begin{array}{l}\text { This } \\
\text { work }\end{array}$ \\
\hline Water & 2 & - & 4 & 4 & 4 & 4 & - & 5 & 4 \\
\hline $\mathrm{Li}+$ & 4 & - & 8 & 7 & 8 & 7 & - & 5 & 7 \\
\hline $\mathrm{Na}+$ & 4 & 6 & 8 & 7 & 8 & 7 & 5.64 & 4 & 7 \\
\hline $\mathrm{K}+$ & 3 & - & 8 & 7 & 8 & 7 & - & 3 & 7 \\
\hline $\mathrm{Rb}+$ & 8 & - & 8 & 8 & - & 7 & - & 3 & 7 \\
\hline $\mathrm{Cs}+$ & 2 & - & - & 10 & - & 7 & - & 4 & 7 \\
\hline F- & 0 & - & - & - & - & 6 & - & 1 & 6 \\
\hline $\mathrm{Cl}-$ & $\mathrm{O}$ & 7 & 7 & 9 & 6 & 6 & 6.98 & 1 & 6 \\
\hline $\mathrm{Br}-$ & 0 & - & 7 & 10 & 6 & 6 & - & 1 & 6 \\
\hline I- & 0 & - & 7 & 12 & 6 & 6 & - & 5 & 6 \\
\hline
\end{tabular}

The objective function used is as follows

$$
O F=\sum_{j=1}^{N_{\gamma_{ \pm}}} W_{\mathrm{j}}\left(\frac{\gamma_{ \pm, j}^{\text {calc }}-\gamma_{ \pm, j}^{\text {exp }}}{\gamma_{ \pm, j}^{\text {exp }}}\right)^{2}+\sum_{j=1}^{N_{v_{ \pm}}} W_{\mathrm{j}}\left(\frac{v_{ \pm, j}^{\text {calc }}-v_{ \pm, j}^{\text {exp }}}{v_{ \pm, j}^{\text {calc }}}\right)^{2}
$$

where $W_{j}$ is the weight of the objective function used to select the impact of the dataset on which parameters are regressed. Their values can be found in table 8 . The parameters $\sigma_{M S A}$ and $\varepsilon^{\text {ass }} / k$ for all ions were regressed simultaneously over MIAC and AMV of all alkali halide i.e. MX (where M is metal ion, and $\mathrm{X}$ is halide ion, for eg. $\mathrm{NaCl}$ ).

As shown in table 6 , two sets of $N_{S}$ are compared along with the final value of the $\varepsilon^{A_{i}}$ and $\sigma_{M S A}$ parameters. The values of $N_{S}$ are smaller in set (2) as compared to set (1). In set (2) where $N_{S}$ are taken from Bockris et al. [101], the final regressed values of $\varepsilon^{A_{i}}$ were extremely high for certain ions (see table 6). This is because the smaller the number of sites, the larger the energy must be to reach the same value for the association energy. In contrast, the final regressed values of $\varepsilon^{A_{i}}$ in set 1 are within a reasonable range. This is clearly due to a smaller number of association sites on that ion. It can be concluded that the $N_{S}$ values from Bockris et al. [102] cannot be used.

The final parameters used in the current work are those of set 1 in table 7. The trends of the regressed diameter $\sigma_{M S A}$ and association energy $\varepsilon^{A_{i}}$ are shown in fig. (5) as compared to the Pauling diameters. It can be seen that cations and anions neatly follow a regular trend except for $\mathrm{Li}^{+}$. The reason for the high value of $\sigma_{M S A}$ of $\mathrm{Li}^{+}$may be due to its small size and high charge density. The association energy $\varepsilon^{A_{i}}$ of $\mathrm{Li}^{+}$ is in decreasing order which is consistent with the decreasing charge density: the higher the charge density 
the higher strength of association between solvent and ion. This is an expected behavior according to work of Simonin et al [140,141]. It can be noticed that the MSA diameters optimized in this work are in good agreement with the MSA diameter values recommended in this prior publication.

Table 6. Final ion parameters sets, $\sigma_{H S}(\AA)$ are fixed equal to Pauling diameter.

\begin{tabular}{|c|c|c|c|c|c|c|c|}
\hline \multirow{2}{*}{ Ion } & $\begin{array}{c}\text { Hard } \\
\text { sphere } \\
\text { diameter }\end{array}$ & \multicolumn{4}{|c|}{ Set 1 } & \multicolumn{3}{c|}{ Set 2 (Bockris et al.) $[101]$} \\
\cline { 2 - 8 } & $\sigma_{H S}(\AA)$ & $N_{S}$ & $\sigma_{M S A}(\AA)$ & $\varepsilon^{A_{i}} / k(K)$ & $N_{S}$ & $\sigma_{M S A}(\AA)$ & $\varepsilon^{A_{i}} / k(K)$ \\
\hline $\mathrm{Li}+$ & 1.2 & 7 & 5.20577 & 5748.85 & 5 & 0.281969 & 23555.2 \\
\hline $\mathrm{Na}+$ & 1.9 & 7 & 2.74386 & 4962.33 & 5 & 2.4962 & 4611.75 \\
\hline $\mathrm{K}+$ & 2.66 & 7 & 2.61254 & 3869.23 & 4 & 12.398 & 4288.29 \\
\hline $\mathrm{Rb}+$ & 2.96 & 7 & 3.72103 & 2967.68 & 3 & 14.4183 & 3806.5 \\
\hline $\mathrm{Cs}+$ & 3.38 & 7 & 5.36451 & 1946.54 & 3 & 1.83048 & 3802.97 \\
\hline $\mathrm{F}-$ & 2.72 & 6 & 1.12055 & 1516.2 & 4 & - & - \\
\hline $\mathrm{Cl}-$ & 3.62 & 6 & 3.38508 & 712.074 & 1 & 1.85746 & 11234.5 \\
\hline $\mathrm{Br}-$ & 3.9 & 6 & 5.6969 & 474.425 & 1 & - & - \\
\hline $\mathrm{I}-$ & 4.32 & 6 & 7.70546 & 89.1208 & 1 & - & - \\
\hline
\end{tabular}
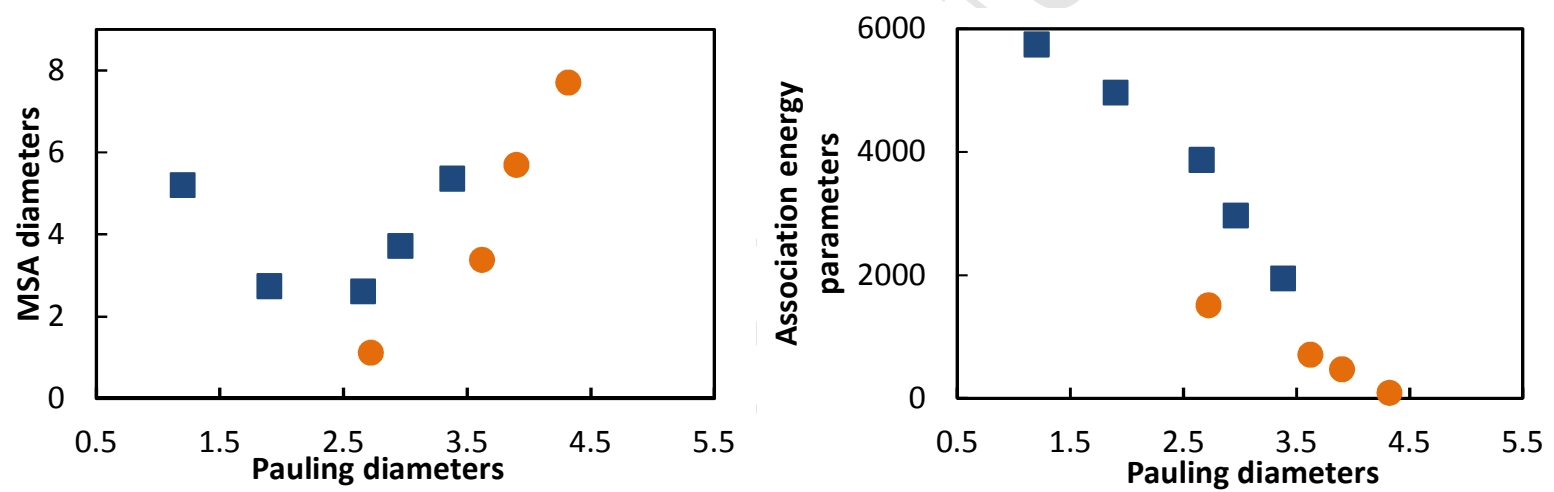

Figure 5 Trend of regressed parameters in comparison to Pauling diameters. (a) MSA diameters vs Pauling diameters(b) association energy $\varepsilon^{A B}$ vs Pauling diameters. ( $\left.\square\right)$ cations $(\bullet)$ anions.

\section{Regression Results}

\subsection{Correlation results for Alkali halide brines}

The regression results of MIAC and densities are presented in fig (6-8) and in table 7 (along with data used for regression and deviations from the model). The results of MIAC show a fairly good agreement with experimental data for 20 alkali halide salts at various temperatures. The deviations are compared from the sets ( 1 and 2 ) given in table 8 . The average deviations for MIAC remain at 3.95\% while it is $24 \%$ for AMV from set 1 using the current model. In contrast, the deviations observed in the work of Rozmus et al. [90] were 2.9\% for MIAC and 30\% for AMV. The mean deviations in MIAC are $1 \%$ larger than those from Rozmus et al. [90], however that work did not take into account the AMV of fluorides which is difficult to correlate. Moreover, improvements in the current work is significant in correlating densities at low salinities and infinite dilution condition which is essential for an improved mixed solvent electrolyte model $[25,68]$. It can be seen that the densities of alkali halides conform fairly well at low salinities which is the capability of the model developed in our previous work [131]. The parameters for the ions that are 
finally used in the model are listed in table 6 (set 1). The only adjustable parameters considered here are MSA ion specific diameters and association energies.

The figure 6 is grouped according to common anions to see varying trends of salt molalities and densities. For salts of chlorides, bromides and iodides, the experimental data for MIAC and calculations from the model follow an increasing trend in the order $\mathrm{Cs}^{+}<\mathrm{Rb}^{+}<\mathrm{K}^{+}<\mathrm{Na}^{+}<\mathrm{Li}^{+}$at a given concentration and at the same temperature. However, this trend is reversed in the case of fluoride salts, which is correctly captured by our model and can be seen in figure $6(\mathrm{~d})$.
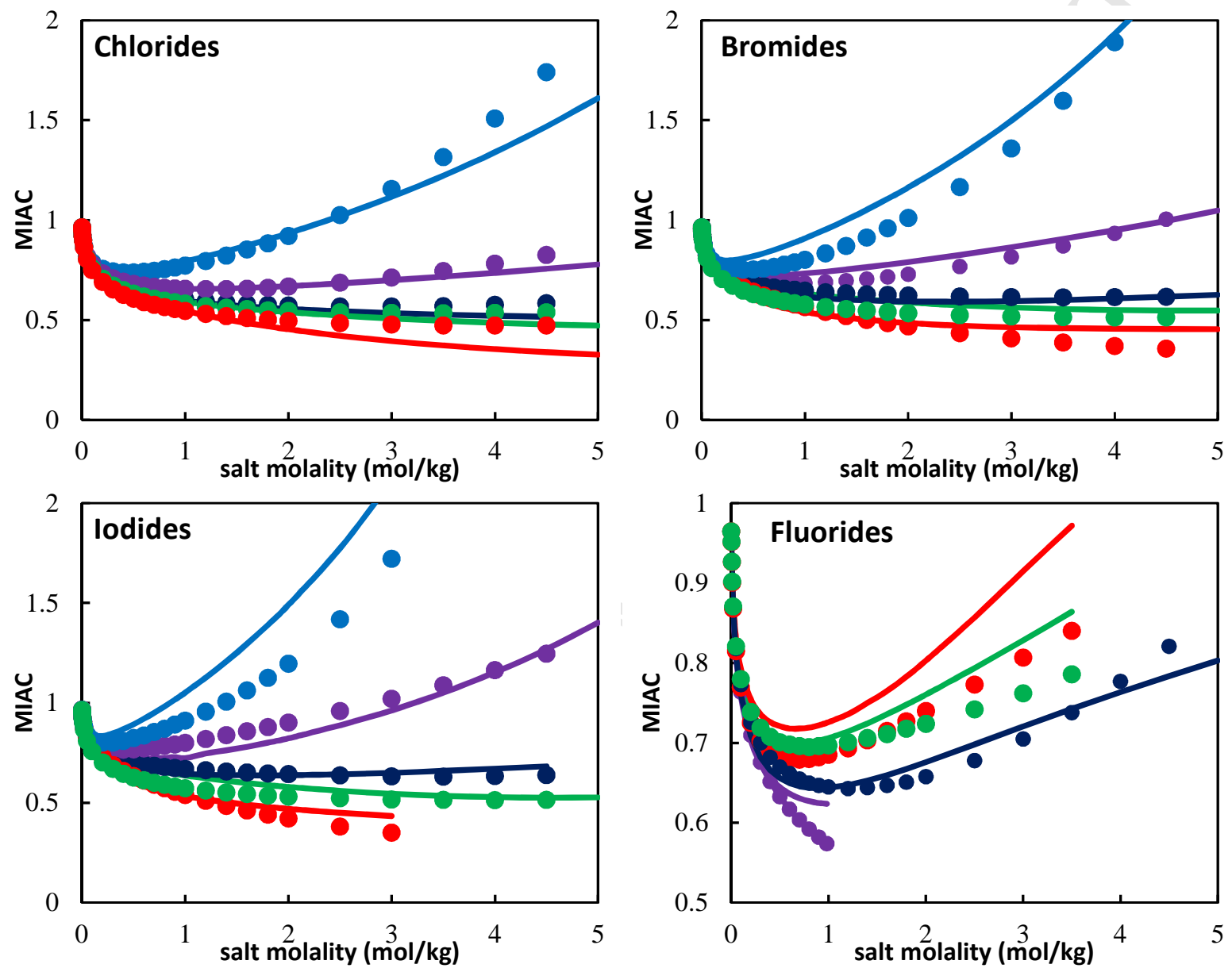

Figure 6 MIAC of aqueous salt solutions at $298.15 \mathrm{~K}$ for alkali halides. The lines represent calculation from model and circles represent experimental data both in the order from top to bottom $(\bullet \mathrm{LiX}, \bullet \mathrm{NaX}, \bullet \mathrm{KX}, \bullet \mathrm{RbX}, \bullet \mathrm{CSX})$ where $\mathrm{X}$ is the alkali halide ion except for fluorides where this order is reversed (no LiF salt not taken).

The reason for the reversed trend of MIAC in alkali fluoride solution is the "localized hydrolysis" as explained by Robinson and Harned [142,143]: fluor acts as a base capturing protonated water thus releasing hydroxyls. Our model does not describe this chemical equilibrium phenomenon. Yet, we can try understanding the phenomenon using the decomposition of the MIAC in its contributing terms which is presented in the figure 7. This figure is drawn to see the effect of fluoride ion (for NaF), whereas fig. 4 is drawn for $\mathrm{NaCl}$. The balance between the various terms is quite different in this case: the association and hard chain terms replace the Born term in positive dominance. This is the result of various factors: the $\varepsilon^{A_{i}}$ of $\mathrm{F}^{-}$is bigger as compared to that of $\mathrm{Cl}^{-}$ion resulting in a large association contribution. Hence, the trends for the Fluorides is for a large part driven by association. Physically, this is consistent with explanation of localized hydrolysis, corresponding to strong interactions between $\mathrm{F}^{-}$ion and water, which is related to the high charge density on fluoride ion. These interactions are correctly taken into account by the 
association term in the ePPC-SAFT model. Other authors [144] have already observed that the physical association term could be used with success to describe chemical equilibria.

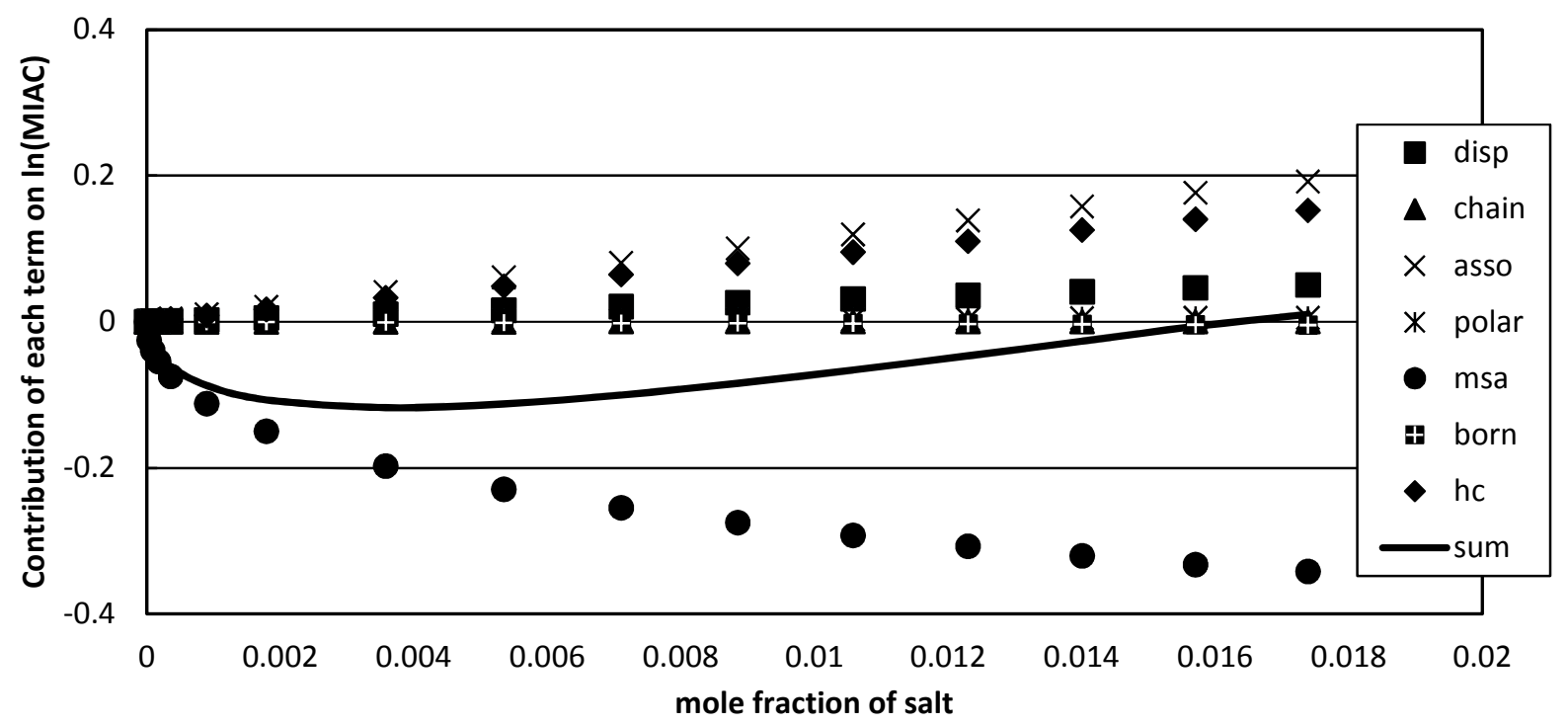

Figure 7 Effect of the various terms on the logarithm of the mean ionic activity coefficient (MIAC) for NaF salt.

The calculation of AMV from the current model showed an average AAD of $30 \%$ as compared to $24 \%$ by Rozmus et al. [90]. However in the work of Rozmus et al. AMV's of fluoride salts were not included in the regression owing to their very high deviations which could have resulted in an even higher average AAD. Likewise, the computed densities that are shown in figure 8 have a very satisfactory behavior. 

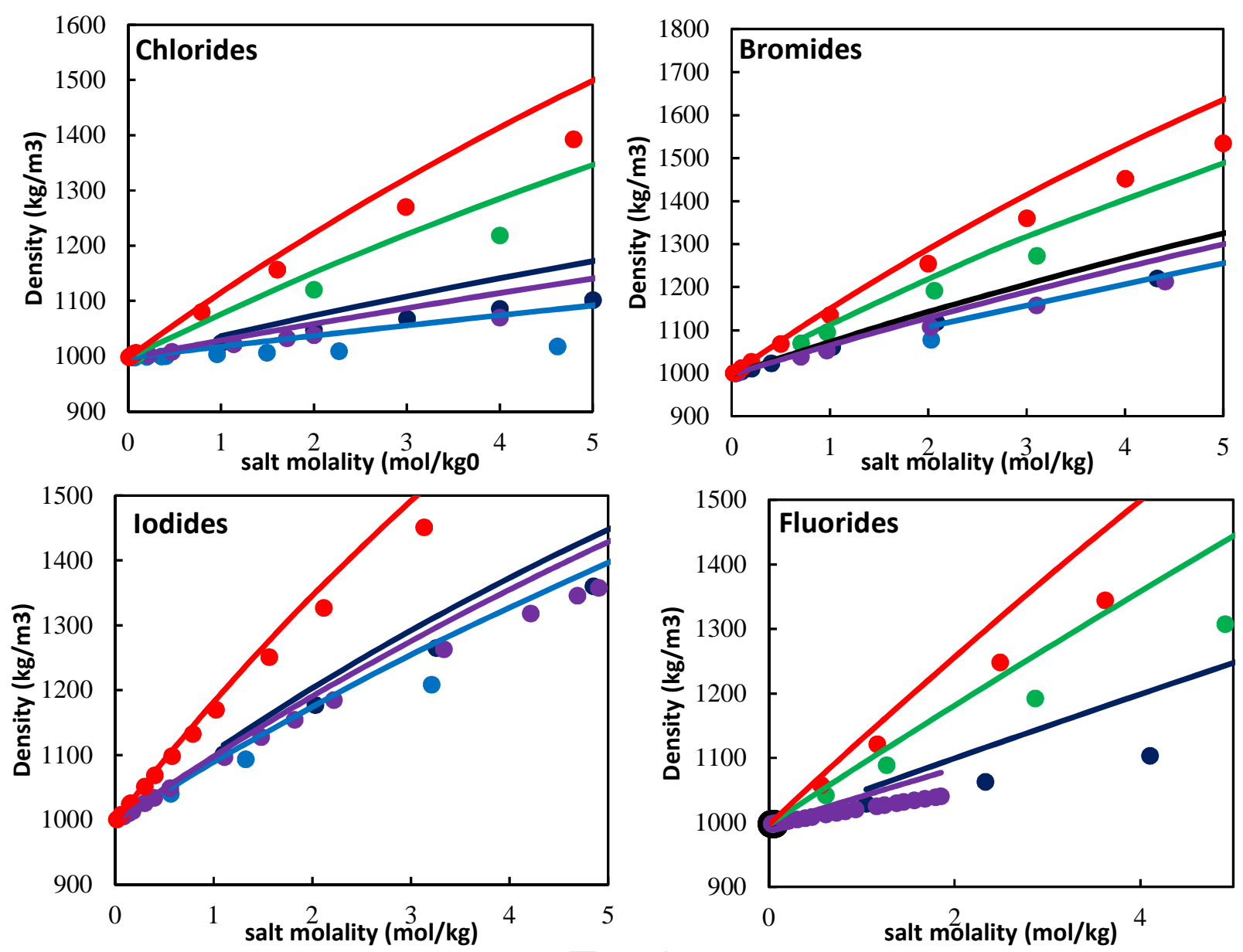

Figure 8 Densities $\left(\mathrm{kg} / \mathrm{m}^{3}\right.$ ) (Y axis) of aqueous salt solutions at $298.15 \mathrm{~K}$ for alkali halides. The lines represent calculation from model and circles represent experimental data both in the order from bottom to top ( $\bullet \mathrm{LiX}, \bullet \mathrm{NaX}, \bullet \mathrm{KX}, \bullet \mathrm{RbX}, \bullet \mathrm{CSX})$ where $\mathrm{X}$ is the alkali halide ion.

Fig. 9 shows the effect of the temperature on the MIAC: when temperature increases, the minimum becomes shallower and the curve levels off. It shows good results for $\mathrm{NaCl}$ and $\mathrm{KCl}$. It is also seen that the experimentally observed trend of MIAC with respect to temperature for $\mathrm{NaCl}$ and $\mathrm{KCl}$ is reproduced. 


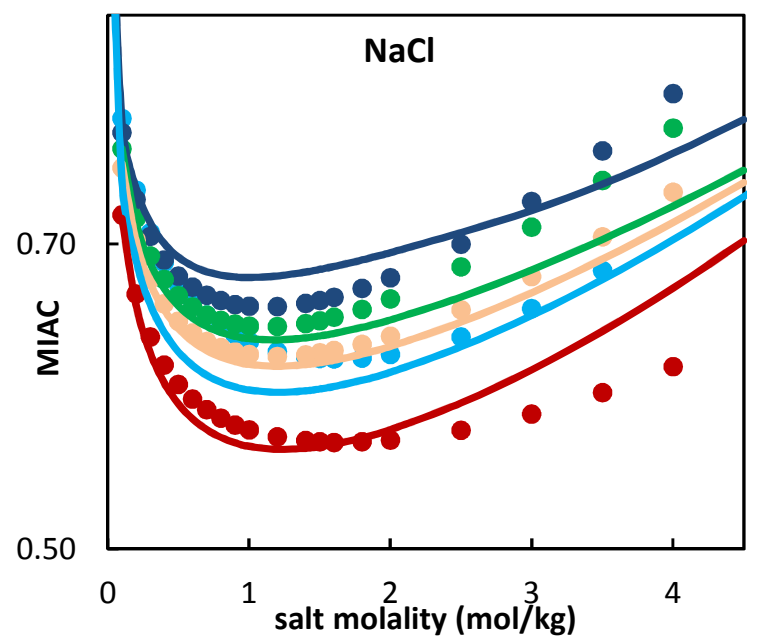

(a)

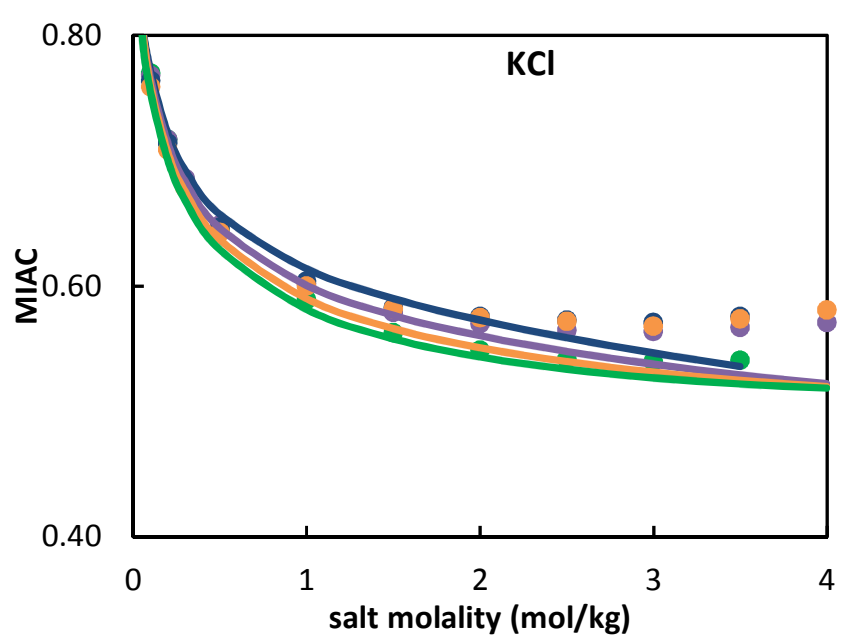

(b)

Figure 9 MIAC of salt aqueous solutions at various temperatures for (a) aq. $\mathrm{NaCl}(\bullet 273.15 \mathrm{~K} \bullet 323.15 \mathrm{~K} \bullet 348.15 \mathrm{~K} \bullet 373.15 \mathrm{~K} \bullet 423.15 \mathrm{~K})(\mathrm{b})$ aq. $\mathrm{KCl}\left(\bullet_{273.15} \mathrm{~K} \bullet_{291.15} \mathrm{~K} \bullet_{308.15} \mathrm{~K} \bullet_{323.15} \mathrm{~K}\right)$ The lines represent calculation from model and circles represent experimental.

The densities of the two salts $\mathrm{NaCl}$ and $\mathrm{NaBr}$ are also presented in the fig. 10, a coherent trend is captured by the model that conforms fairly well to the experimental data. It may be observed that the slope of the experimental densities flattens at higher salt molalities, whereas the model does not capture this trend.
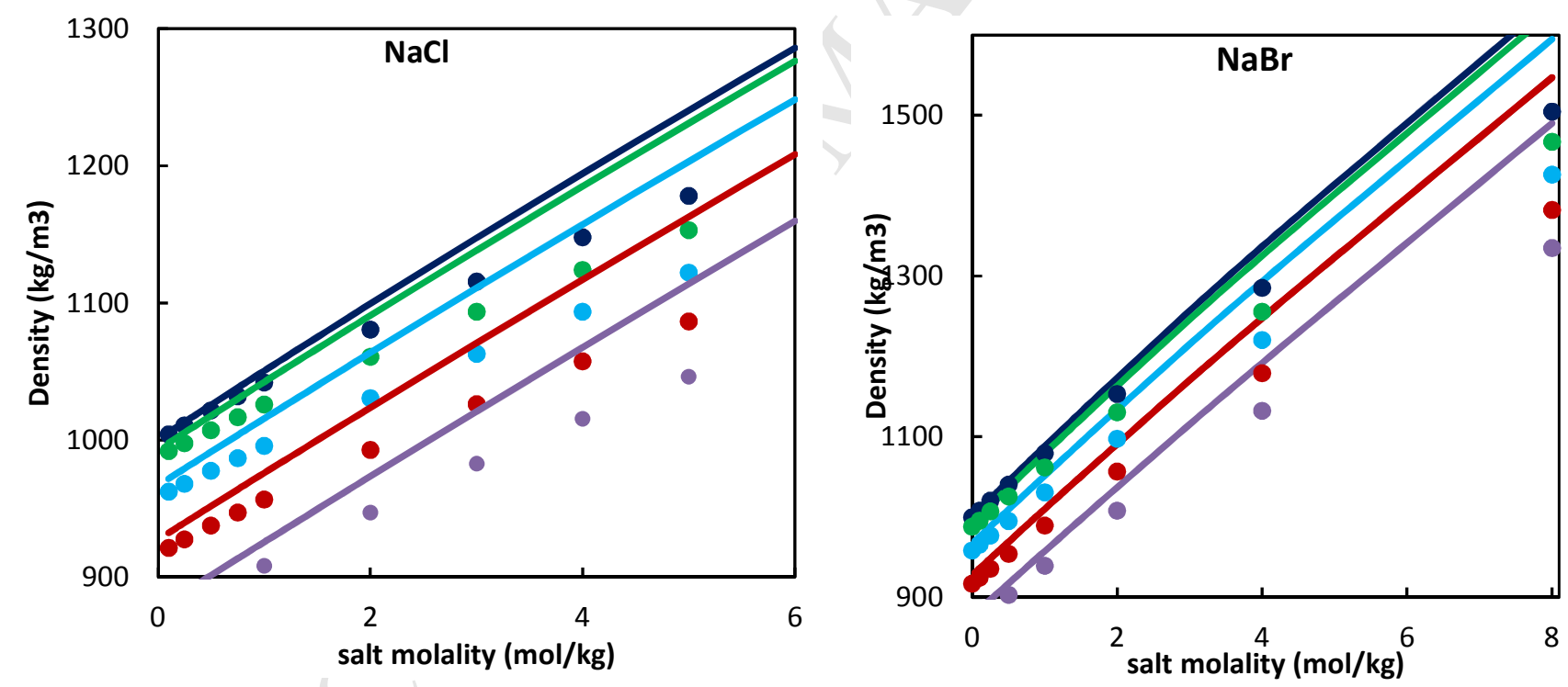

Figure 10 Liquid density $\left(\mathrm{kg} / \mathrm{m}_{3}\right)$ of salt aqueous solutions at various temperatures. The lines represent calculation from model and circles represent experimental. $\left(\bullet_{273.15} \mathrm{~K} \bullet 323.15 \mathrm{~K} \bullet 373.15 \mathrm{~K} \bullet 423.15 \mathrm{~K} \bullet 473.15 \mathrm{~K}\right)$ 


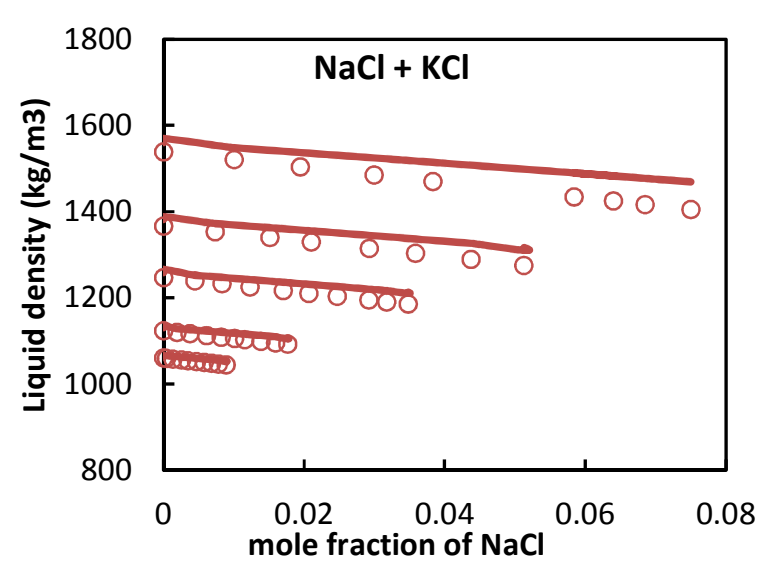

(a)

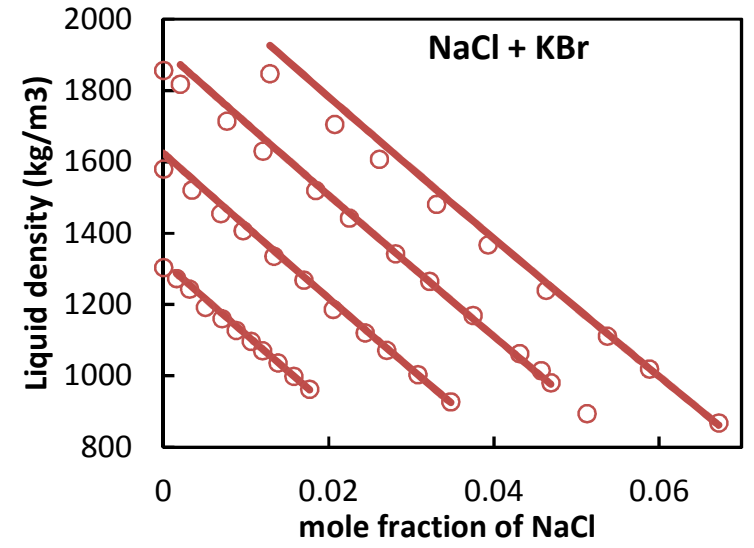

(b)

Figure 11 Liquid densities of aqueous (a) $\mathrm{NaCl}+\mathrm{KCl}$ system and aqueous (b) $\mathrm{NaCl}+\mathrm{KBr}$ system $298.15 \mathrm{~K}$ and varying salt molalities. The figure is plotted against mole fraction of $\mathrm{NaCl}$ while each line is at fixed total salt concentration. Points are experimental data $[145,146]$ and lines are prediction from model.

In fig. 11 multi salts $(\mathrm{NaCl}+\mathrm{KCl}$ and $\mathrm{NaCl}+\mathrm{KBr})$ aqueous solution densities predictions are compared to the corresponding experimental liquid densities at $298.15 \mathrm{~K}$. It should be recalled here that the calculations are predictions from the model by using only ion specific parameters and no additional parameter was fitted for these systems. The model also correctly captures the variation in liquid density as a result of varying composition of two salts within the same system. The accuracy is rather good at molalities below $2 \mathrm{~mol} \mathrm{~kg}^{-1}$. Above this salt concentration, the model steadily overestimates the densities (which is in accordance with the observations of figure 8). The global deviation remains below around 3\%.

In table 8, the absolute average deviation (AAD) for MIAC and AMV are summarized for all alkali halide salts at various temperatures along with the source of experimental data.

Table 7. Apparent Molar Volumes (AMV), Mean Ionic Activity Coefficients (MIAC), and densities at 298 K, experimental Data, correlations, and calculations.

\begin{tabular}{|c|c|c|c|c|c|c|c|c|}
\hline \multirow[b]{2}{*}{ Salt } & \multicolumn{2}{|c|}{$\begin{array}{l}\text { Number of points and } \\
\text { weight }\end{array}$} & \multicolumn{2}{|c|}{ Maximum molality } & \multicolumn{2}{|c|}{$\begin{array}{c}\text { Deviation } \\
(\% A A D) \text { set \#1 }\end{array}$} & \multicolumn{2}{|c|}{ References } \\
\hline & $\begin{array}{c}\text { AMV } \\
W=0.2 \\
\text { for all }\end{array}$ & $\begin{array}{c}\text { MIAC } \\
\mathrm{W}=1.0 \text { for } \\
\text { all }\end{array}$ & AMV & MIAC & AMV & MIAC & AMV & MIAC \\
\hline \multicolumn{9}{|c|}{ Lithium Halides } \\
\hline $\mathrm{LiF}$ & 17 & - & 0.03 & - & 7.6 & - & {$[147]$} & [148] \\
\hline $\mathrm{LiCl}$ & 16 & 27 & 12.2 & 5 & 3.09 & 3.89 & {$[149,150]$} & [148] \\
\hline $\mathrm{LiBr}$ & 5 & 27 & 10 & 5 & 14.15 & 1.60 & {$[151]$} & [148] \\
\hline LiI & 4 & 23 & 3.1 & 3 & 20.39 & 2.7 & {$[152]$} & {$[148]$} \\
\hline \multicolumn{9}{|c|}{ Sodium Halides } \\
\hline $\mathrm{NaF}$ & 24 & 16 & 0.93 & 1 & 9.85 & 5.85 & [147] & {$[148]$} \\
\hline $\mathrm{NaCl}$ & 12 & 27 & 6.1 & 5 & 2.84 & 6.21 & {$[153,154]$} & [148] \\
\hline $\mathrm{NaBr}$ & 11 & 27 & 8 & 5 & 12.59 & 4.05 & $\begin{array}{c}{[151,155,1} \\
56]\end{array}$ & [148] \\
\hline $\mathrm{NaI}$ & 21 & 27 & 9.7 & 5 & 18.20 & 3.66 & [157-159] & {$[148]$} \\
\hline \multicolumn{9}{|c|}{ Potassium Halides } \\
\hline $\mathrm{KF}$ & 10 & 27 & 12.7 & 5 & 57.15 & 2.06 & [16o] & [148] \\
\hline $\mathrm{KCl}$ & 9 & 26 & 4.5 & 4.5 & 36.90 & 1.53 & {$[161]$} & [148] \\
\hline $\mathrm{KBr}$ & 9 & 27 & 4.4 & 5 & 40.06 & 2.33 & [162] & [148] \\
\hline $\mathrm{KI}$ & 11 & 26 & 8 & 4.5 & 40.89 & 1.93 & [163] & [148] \\
\hline \multicolumn{9}{|c|}{ Rubidium Halides } \\
\hline
\end{tabular}




\begin{tabular}{|c|c|c|c|c|c|c|c|c|}
\hline $\mathrm{RbF}$ & 12 & 24 & 11.7 & 3.5 & 34.77 & 4.42 & {$[160]$} & {$[148]$} \\
\hline $\mathrm{RbCl}$ & 6 & 27 & 6 & 5 & 27.46 & 2.42 & {$[164]$} & {$[148]$} \\
\hline $\mathrm{RbBr}$ & 7 & 27 & 4.5 & 5 & 31.66 & 3.10 & {$[156]$} & {$[148]$} \\
\hline $\mathrm{RbI}$ & - & 27 & - & 5 & & 4.52 & & {$[148]$} \\
\hline \multicolumn{7}{|c|}{ Cesium Halides } \\
\hline $\mathrm{CsF}$ & 11 & 24 & 16.1 & 3.5 & 36.62 & 4.44 & {$[160]$} & {$[148]$} \\
\hline $\mathrm{CsCl}$ & 16 & 27 & 10.6 & 5 & 24.26 & 7.55 & {$[155,160]$} & {$[148]$} \\
\hline $\mathrm{CsBr}$ & 13 & 27 & 4.1 & 5 & 29.73 & 7.20 & {$[165]$} & {$[148]$} \\
\hline $\mathrm{CsI}$ & 13 & 23 & 2.3 & 3 & 32.35 & 5.67 & {$[166]$} & {$[148]$} \\
\hline
\end{tabular}

\subsection{Solvation Gibbs energies for Alkali halide brines}

The Gibbs energy of solvation discussed in section 2.3.1 is an interesting property to examine. When ions are dissolved in water from the ideal gas at infinite dilution, and the same molar volume, we showed that several effects are combined resulting in a change in Gibbs energy, called the Gibbs energy of solvation. In table 9 we show the $\Delta G_{s, \text { salt }}$ predicted by the current model using parameters in table 7 (set 1). The $\Delta G_{s, \text { salt }}$ is defined as the sum of the $\Delta G_{s}$ of the cation and the anion (eq. 29).

$$
\Delta G_{s, \text { salt }}=\Delta G_{s, \text { cation }}+\Delta G_{s, \text { anion }}
$$

where $\Delta G_{s, i o n}$ is computed according to eqn. 11. The results are compared to result from Das et al. [25], Schreckenberg et al. [68] and Galindo et al. [77][25]. The first work used a non-primitive model (treats solvent as molecules) while the latter two consider ions in a dielectric continuum. The results presented in table 8 show that the capability of the current model to describe the solvation is qualitatively good, however, the values as those obtained by Das et al. [25] are far better. This can be due to the fact that the current model uses only two ion specific parameters while Das et al. [25] used an additional water-salt binary parameter along with two other parameters per ion. As was shown in section 2.4.1, the largest contribution to the solvation energy is the Born term. The ionic diameter used in this term has obviously a large effect on the solvation Gibbs energy. Nevertheless, it was chosen to keep this diameter equal to the Pauling diameter so as to reduce the number of adjustable parameters.

Table 8. Gibbs energy of solvation $\Delta G_{s, s a l t}$ for alkali halides. Experimental data compared to calculation from the model (our model vs SAFT-VR+DE[25] vs SAFT-VRE[77][25] vs SAFT-VRE[68].

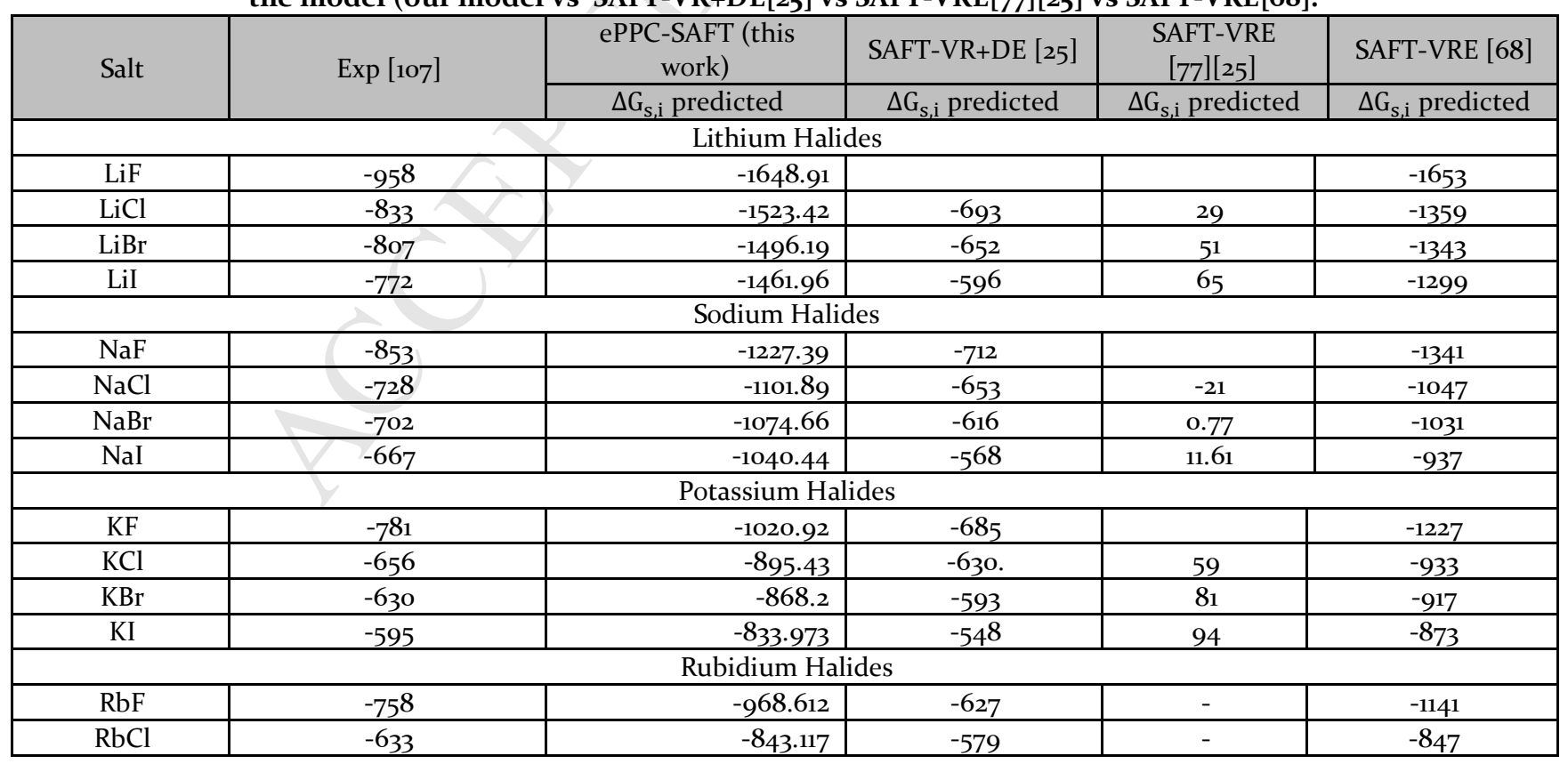




\begin{tabular}{|c|r|r|r|r|r|}
\hline $\mathrm{RbBr}$ & -607 & -815.887 & -547 & - & -831 \\
\hline $\mathrm{RbI}$ & -572 & -781.66 & -508 & - & -787 \\
\hline \multicolumn{6}{|c|}{ Cesium Halides } \\
\hline $\mathrm{CsF}$ & -735 & -910.975 & -605 & - & - \\
\hline $\mathrm{CsCl}$ & -610 & -785.479 & -556 & - & - \\
\hline $\mathrm{CsBr}$ & -584 & -758.249 & -527 & - & - \\
\hline $\mathrm{CsI}$ & -549 & -724.023 & -487 & - & - \\
\hline
\end{tabular}

\section{Alkanes and acid gases with brines: salting out effect in presence of organic compounds}

It is well known that the solubility of organic compounds in water decreases upon addition of salts. This is called the salting-out effect. It can be presented in the form of solubility curves (figure 12) or in terms of average deviations (table 9). The systems investigated here are water + salt + methane/ethane/ $\mathrm{CO}_{2} / \mathrm{H}_{2} \mathrm{~S}$. The pure component parameter for methane, ethane, $\mathrm{CO}_{2}$, and $\mathrm{H}_{2} \mathrm{~S}$ are listed in table 5. A binary parameter $k_{i j}$ (for water-alkanes) and $w_{i j}, u_{i j}$ (for $\mathrm{CO}_{2} / \mathrm{H}_{2} \mathrm{~S}$-alkanes) are regressed using the experimental data $[167,168]$ of the solubility of methane/ethane/light gases in water using the objective function given eq. 29.

$$
O F=\sum_{j=1}^{N_{\mathrm{P}} \sigma}\left(\frac{\mathrm{P}^{\sigma c a l c}-\mathrm{P}^{\sigma e x p}}{\mathrm{P}^{\sigma \exp }}\right)^{2}
$$

Table 10 presents for each system studied the binary interaction parameters fitted and the average deviations obtained along with binary/ternary system parameters and experimental data.

When a salt like $\mathrm{NaCl}$ is added into the water + gas system, it decreases the solubility of the gas in water. This behavior is the so-called salting out phenomenon. It is difficult to capture using electrolytes EoS [66]. Our model showed a systematic underprediction of bubble pressure. It was therefore found necessary to adjust an additional parameter between the ions and the gaseous solute. Since the ions have no dispersive energy, it is impossible to use a $k_{i j}$ for this purpose. This is why the non-additive diameter contribution developed by Trinh and coworkers [120] was used. This correction describes the fact that the cross-diameter is different from the arithmetic average of the two pure component diameters. It was developed in the context of hydrogen dissolution in polar compounds, using the argument that due to the polarity, the shape of the hydrogen molecule would deform. It can be argued that the presence of ions is even more disturbing than a simple dipole moment for a neutral molecule. Hence, in the presence of an ionic charge, the polarizable molecule will be distorted in such a way that the arithmetic average of the diameters may need to be modified. This can be achieved using the $l_{i j}$ binary interaction parameter.

By regressing the gas-ion $l_{i j}$ parameters, the quality of the results is improved as shown in fig 12. This parameterization is performed on the ternary vapor liquid equilibrium data of several systems given in table 10 and are given in table 10 along with average deviations, temperature range, and the experimental data used for regression. In order to have a transferable set of parameters for gas-ion pairs, the systems of a gas with all available salts are taken at once and all ion-gas parameters are regressed simultaneously. This gives gas-ion parameters that are not system specific and can be used when studying system of salts having different ions.

The values of the regressed parameters $l_{i j}$ between solute-ion pairs are generally small except for $\mathrm{Li}^{+}$for which the $l_{i j}$ was fixed to 0.5 in order to avoid computational difficulties. Such a large value would indicate that the cross diameter of the methane and $\mathrm{Li}^{+}$pair is strongly reduced compared to the arithmetic average. For the remaining ions as can be seen in the table 10 the value of $l_{i j}$ remains very 
small in absolute value. It is found to be generally positive for cations and negative for anions. The numerical values of the corrections show no clear trend, however, so that no predictive strategy could be identified.

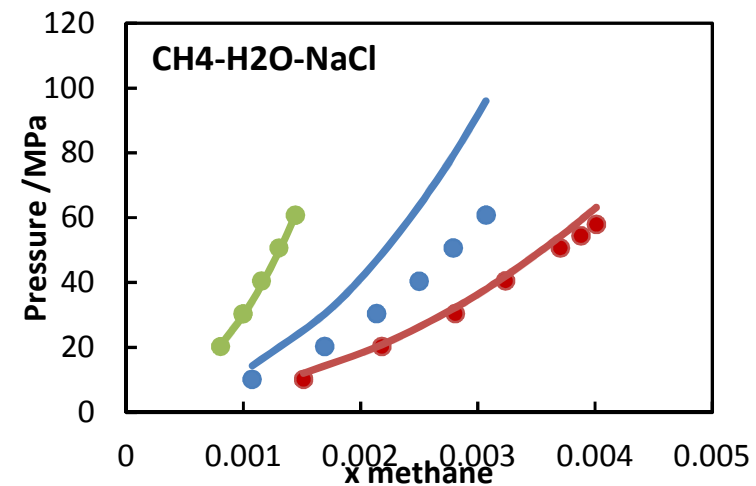

(a)

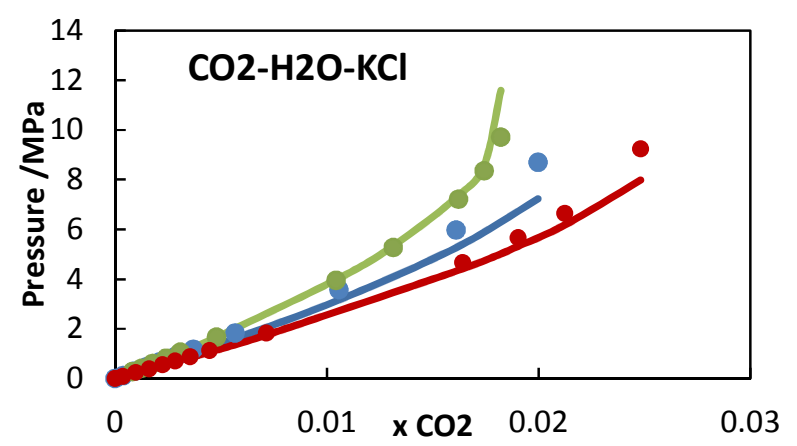

(c)

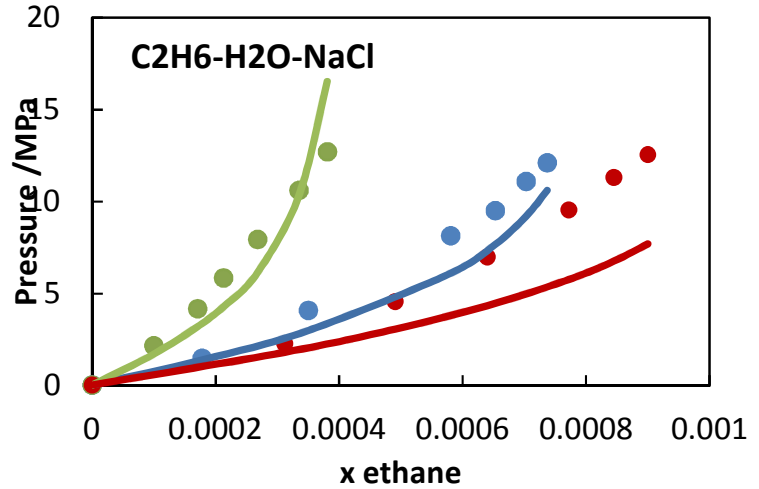

(b)

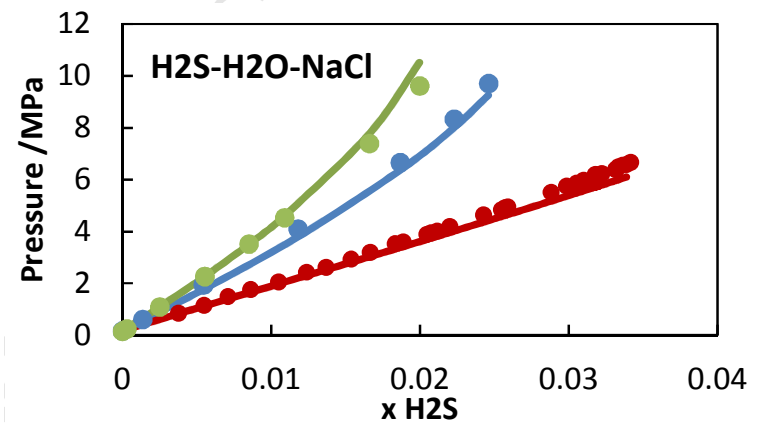

(d)

Figure 12 Solubility of alkanes and acid gases in water at two different salt concentrations red(o molal) blue (1 molal) green (4 molal) for systems (a) $\mathrm{CH}_{4}-\mathrm{H}_{2} \mathrm{O}-\mathrm{NaCl}$ system at $324 \mathrm{~K}$ (b) $\mathrm{C}_{2} \mathrm{H} 6-\mathrm{H}_{2} \mathrm{O}-\mathrm{NaCl}$ system at $353 \mathrm{~K}$ (c) $\mathrm{CO}_{2}-\mathrm{H}_{2} \mathrm{O}-\mathrm{KCl}$ system at $313 \mathrm{~K}$ (d) $\mathrm{H}_{2} \mathrm{~S}-\mathrm{H}_{2} \mathrm{O}-\mathrm{NaCl}$ system at $393 \mathrm{~K}$

Carbon dioxide $\left(\mathrm{CO}_{2}\right)$ with brines has been investigated extensively due to the possibility of injection into saline aquifers principally for carbon capture and sequestration. Mineral rock containing salts dissolve in water and interact with $\mathrm{CO}_{2}$. In Enhanced Oil Recovery (EOR) techniques, $\mathrm{CO}_{2}$ is also viewed as a potential gas to pressurize the reservoir, where brines are naturally present. An increasing number of studies has been published, both providing new experimental data [169-171] and proposing thermodynamic models [90,172-174] which provide accurate representations of $\mathrm{CO}_{2}$ brine phase equilibrium. In the current work water $+\mathrm{CO}_{2}+\mathrm{NaCl} / \mathrm{KCl}$ systems are investigated (table 9) with our model. It gives a fairly accurate description of the phase behavior of these systems.

A cross interaction parameter $w_{i j}$ on the association energy between $\mathrm{CO}_{2}$ and water was first fitted to obtain accurate results on salt-free system (table 10). Adding ionic species associative bonds may be created between them and $\mathrm{CO}_{2}$, according to the combining rules (equations2o and 21). Adjusting the cross-association parameters between $\mathrm{CO}_{2}$ and ions did not improve the results so it was decided to work on the $l_{i j}$ cross interaction parameter in the same way as for alkanes (data reference and results are shown in table 9). The salting out effect is observed as the the model fits the experimental data (figure 11). The result are shown at $313 \mathrm{~K}$. A change in slope in the bubble pressure is observed for 4.0 molal salt at $323.15 \mathrm{~K}$ due to a transition from vapor-liquid to liquid-liquid region.

Another system studied in the current work is $\mathrm{H}_{2} \mathrm{~S}$ with brine at $393.15 \mathrm{~K}$ (figure 15). This compound also shows associative cross-interactions with ions. Yet, in the same way as for other systems a 
non-additive $l_{i j}$ binary interaction parameter between $\mathrm{H}_{2} \mathrm{~S}$ and each ion was fitted on experimental saturation pressures of salted system. The current model is able to give fairly accurate description of the system as compared to experimental data.

Table 9. Table for AAD, binary and ternary system parameter for alkane/acid gases-water-salt systems.

\begin{tabular}{|c|c|c|c|c|c|}
\hline System & parameters & $N_{P}$ & $\mathrm{~T}(\mathrm{~K})$ range & $\begin{array}{l}\text { Average } \\
\text { AAD }(\%)\end{array}$ & $\begin{array}{l}\text { Experimen } \\
\text { tal data }\end{array}$ \\
\hline (1) Methane + (2) water + & $k_{i j}=-0.027827$ & 94 & $298.15-373.15$ & & {$[175]$} \\
\hline \multirow{5}{*}{$\begin{array}{l}\text { (3) } \mathrm{NaCl} \\
\text { (3) } \mathrm{KCl} \\
\text { (3) } \mathrm{LiCl} \\
\text { (3) } \mathrm{LiBr} \\
\text { (3) } \mathrm{KBr}\end{array}$} & \multirow{5}{*}{$\begin{array}{l}l_{i j}\left(\mathrm{CH}_{4} \text {-ion }\right) \\
\mathrm{Li}^{+}: 0.5 \\
\mathrm{Na}^{+}:-0.1909 \\
\mathrm{~K}^{+}: 0.0663 \\
\mathrm{Cl}^{-}: 0.06123 \\
\mathrm{Br}^{-}:-0.01521\end{array}$} & 46 & 313,353 & 19.74 AADP & {$[176][177]$} \\
\hline & & 94 & $313,353,373$ & 18.79 AADP & {$[151]$} \\
\hline & & 45 & 313,353 & 19.03 AADP & {$[151]$} \\
\hline & & 51 & 313,353 & 17.08 AADP & {$[151]$} \\
\hline & & 35 & 313,353 & 16.21 AADP & {$[151]$} \\
\hline \multirow{3}{*}{$\begin{array}{l}\text { (1) Ethane } \\
\text { (3) } \mathrm{NaCl} \\
\text { (3) } \mathrm{KCl}\end{array}$} & $k_{i j}=-0.002845$ & 50 & $298.15-423.15$ & 34 AADP & {$[178,179]$} \\
\hline & \multirow{2}{*}{$\begin{array}{l}l_{i j}\left(\mathrm{C}_{2} \mathrm{H}_{6} \text {-ion }\right) \\
\mathrm{Na}^{+}: 0.629 \\
\mathrm{~K}^{+}: 0.4790 \\
\mathrm{Cl}^{-}:-0.48735\end{array}$} & 14 & 353 & 17.35 AADP & {$[177]$} \\
\hline & & 14 & 353 & 10.06AADP & [177] \\
\hline \multirow[t]{2}{*}{ (1) $\mathrm{H}_{2} \mathrm{~S} \quad+(2)$ water +} & $w_{i j}=0.1856$ & 325 & $283-453$ & 6.4 AADP & [180] \\
\hline & $\begin{array}{l}l_{i j}\left(\mathrm{H}_{2} \mathrm{~S} \text {-ion }\right) \\
\mathrm{Na}^{+}: 0.00618 \\
\mathrm{Cl}^{-}:-0.0964\end{array}$ & 17 & 393 & 5.8 AADP & {$[181]$} \\
\hline \multirow{3}{*}{$\begin{array}{l}\text { (1) } \mathrm{CO}_{2} \\
\text { (3) } \mathrm{NaCl} \\
\text { (3) } \mathrm{KCl}\end{array}$} & $w_{i j}=0.127$ & 68 & $298.15-353.15$ & 14.7 AADP & [177] \\
\hline & \multirow{2}{*}{$\begin{array}{l}l_{i j}\left(\mathrm{CO}_{2} \text {-ion }\right) \\
\mathrm{Na}^{+}: 0.0985 \\
\mathrm{~K}^{+}: 0.0541 \\
\mathrm{Cl}^{-}:-0.2524\end{array}$} & 70 & 313,353 & 7.07 AADP & [182] \\
\hline & & 96 & 313,353 & 10.34 AADP & [182] \\
\hline
\end{tabular}

AADP: Average absolute deviation in vapor pressure (see definition in the list of abbreviations)

\section{Mixed solvent electrolytes}

Since we have seen that the model is able to describe the salting-out phenomena in alkane or acid gas + brine systems, it can now be used to study vapor-liquid equilibrium of various mixed solvent salt systems. Pure water and several pure solvents such as methanol/ethanol/1-propanol have been already parameterized in a previous work [131] and parameters are recalled in table 3. Binary mixture of methanol-water were parameterized using cross interaction parameters $\left(w_{i j}, u_{i j}\right.$ and $\left.l_{i j}\right)$, here three parameter were chosen to have better accuracy in the description of binary phase equilbria (without fitting $l_{i j}$, deviations were close to $10 \%$ in AADP and AADY, compared to $1.8 \%$ when including this additional correction).

Several mixed solvent systems have also been studied previously by many authors [25,54,68,183-185]. However, most of them rely on fitting an additional solvent-salt/ion dispersion parameter. In this work, the results are purely predictive in nature since all parameters have been determined previously.

As seen in figure 13, the predictions from the model agree fairly well with experimental data. It is also seen that there is a systematic under-prediction of bubble temperatures at the composition of alcohols between 0.2 and 0.4 . This is due to the effect of salt on the vapor-liquid equilibria of mixed solvent systems [186,187]. Figure 13-14 show the results with mixed solvent (methanol/ethanol) salt systems. The salt molality is however rather small because the salt solubility in methanol is small [188]. The blue line indicates salt-free system. Upon addition of salt the pure water boiling temperature increases, but 
interestingly the mixture bubble temperature decreases. This trend can be seen in all the methanolwater-salt systems in fig. 13. The similar trend is also observed in ethanol-water-salt systems in Figure 14.

In table 10 the vapor-liquid equilibrium results of several alcohol-water-salt systems is summarized, reporting average deviations, temperature ranges and the source of experimental data. For most systems, the deviations lie, in pressure below $1 \%$ and in composition below $10 \%$.

A quaternary system of $\mathrm{CO}_{2}$-water-methanol- $\mathrm{NaCl}$ is also tested predictively. The vapor-liquid equilibrium is predicted by the model by utilizing only binary parameters between methanol-water, $\mathrm{CO}_{2}$-water and $\mathrm{CO}_{2}$-ions. The average deviations in vapor pressure were $14.5 \%$ AADP, this indicated that model can predictively estimate VLE of quaternary systems with satisfactory accuracy.

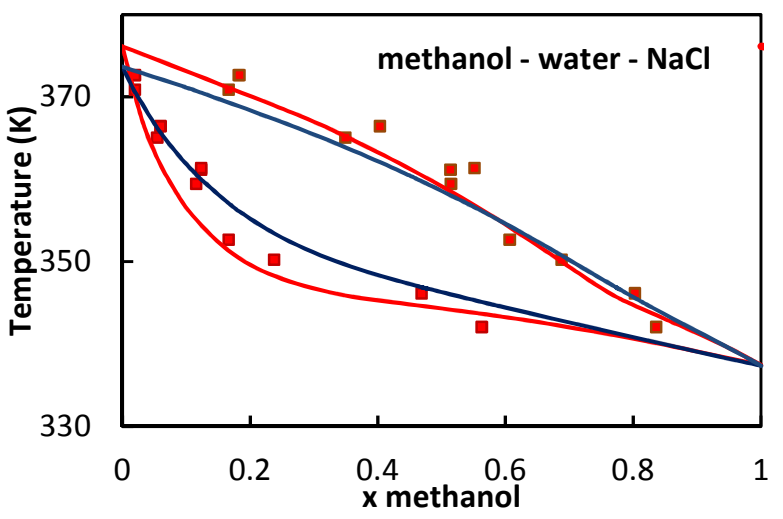

(a)

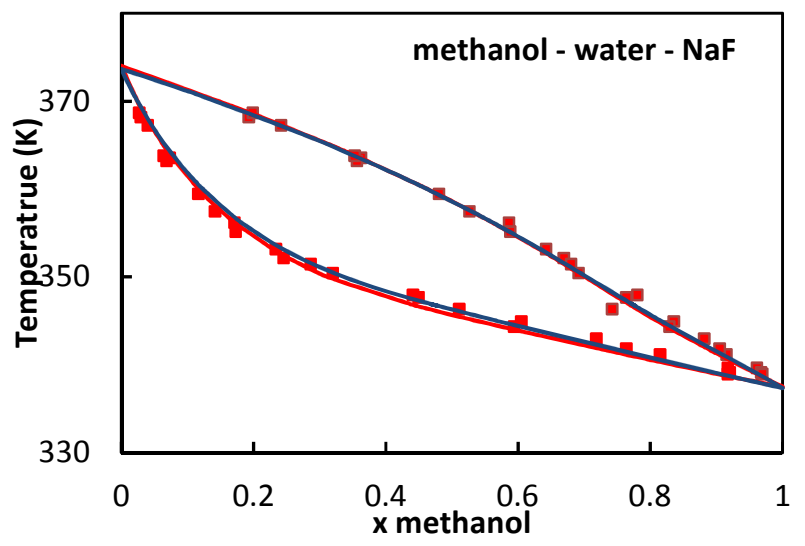

(c)

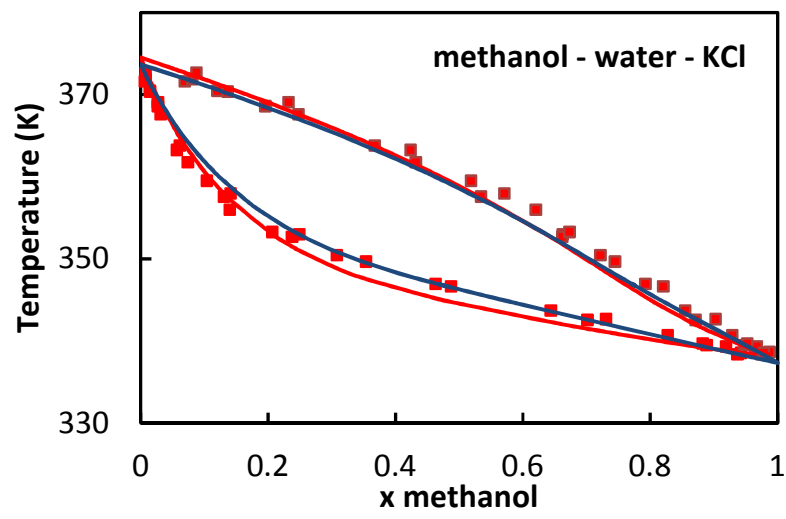

(b)

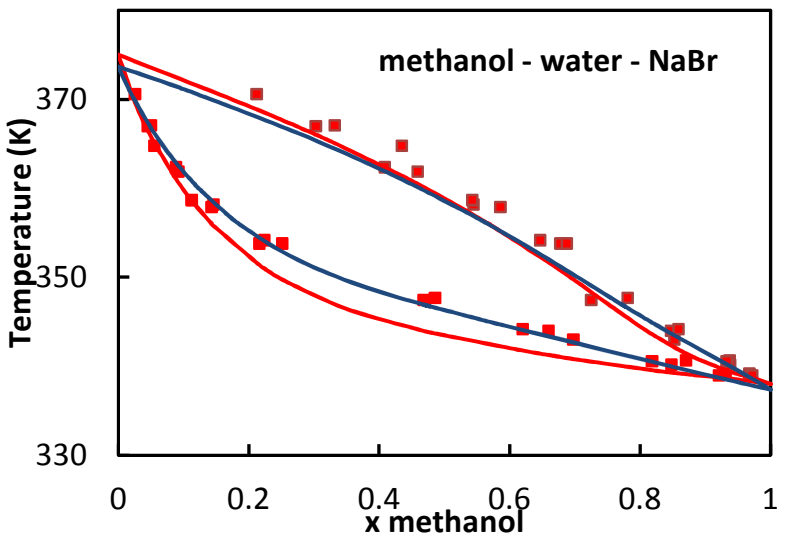

(d)

Figure 13 Isobaric Vapor-liquid equilibrium of Methanol-Water-salt system at 1 bar. Lines are prediction from model and point are experimental data. (a) water-methanol-NaCl system at varying salt molalities (upto 2.56 molal) (blue line indicates salt-free systems (water-methanol) (b) water-methanol-KCl system at varying salt molalities (o.1-2 molal) in experimental data the model prediction at 2 molal concentration of salt to obtain a smooth curve at uniform salt concentration. (c) water-methanol-NaF system at varying salt molalities(0.2-0.5) in experimental data but model prediction at 0.5 molal concentration of salt to obtain a smooth curve at uniform salt concentration. (d) water-methanol-NaBr system at varying salt molalities(0.01-3.5 molal) in experimental data but model prediction at 2.0 molal concentration of salt to obtain a smooth curve at uniform salt concentration. 


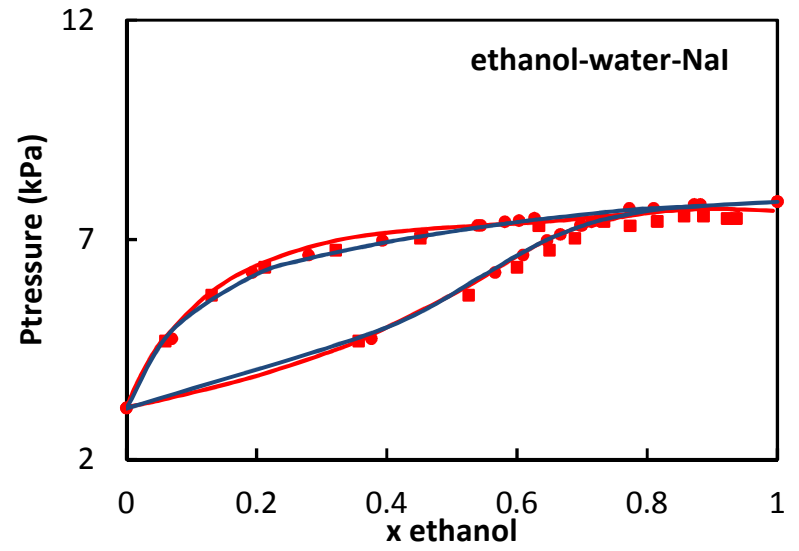

(a)

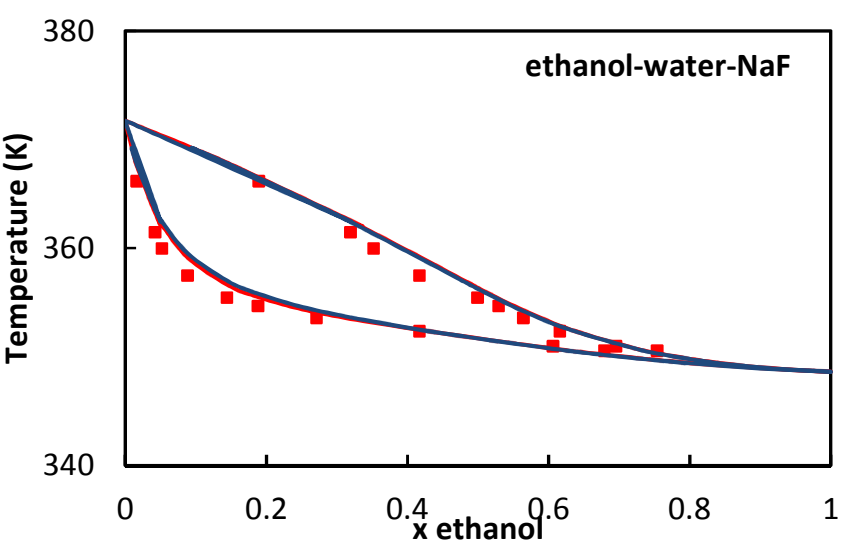

(b)

Figure 14 (a) Isothermal Vapor-liquid equilibrium of Ethanol-Water-NaI system at 298.15K. Lines are prediction from model at 0.5 molal and point are experimental data at varying molalities (upto 1.35) (blue line indicates no salt systems (water-ethanol) (b) water-ethanol-NaF system at varying salt molalities (up to 0.82 ) at 1 bar.

Table 10. Summary of AAD, binary system parameters for VLE of alcohol-water-salt systems.

\begin{tabular}{|c|c|c|c|c|c|}
\hline System & $\begin{array}{l}\text { Parameter } \\
\text { (water-alcohol) }\end{array}$ & $N_{P}$ & $\mathrm{~T}(\mathrm{~K})$ range & $\begin{array}{l}\text { Average AAD } \\
(\%)\end{array}$ & $\begin{array}{l}\text { Experimental } \\
\text { data }\end{array}$ \\
\hline (1) Methanol + (2) water + & $\begin{array}{l}w_{i j}=0.0352 \\
u_{i j}=0.0025 \\
l_{i j}=0.0178\end{array}$ & 58 & $\begin{array}{l}298.15- \\
403.15\end{array}$ & $\begin{array}{l}1.83 \text { AADP } \\
1.71 \text { AADY }\end{array}$ & {$[189]$} \\
\hline (3) $\mathrm{LiCl}$ & - & 12 & 333.15 & $\begin{array}{l}0.76 \text { AADT } \\
4.54 \text { AADY }\end{array}$ & [190] \\
\hline (3) $\mathrm{NaF}$ & - & 25 & $\begin{array}{l}338.95- \\
368.65\end{array}$ & $\begin{array}{l}0.20 \text { AADT } \\
3.33 \text { AADY }\end{array}$ & {$[186,191]$} \\
\hline (3) $\mathrm{NaCl}$ & & 11 & $\begin{array}{l}342.05- \\
372.65\end{array}$ & $\begin{array}{l}\text { o.81 AADT } \\
\mathbf{2 . 3 4} \text { AADY }\end{array}$ & {$[186,191]$} \\
\hline (3) $\mathrm{NaBr}$ & - & 20 & $\begin{array}{l}338.95- \\
370.55\end{array}$ & $\begin{array}{l}.28 \text { AADT } \\
3.47 \text { AADY }\end{array}$ & [192] \\
\hline (3) $\mathrm{KCl}$ & - & 31 & $\begin{array}{l}338.35- \\
372.65\end{array}$ & $\begin{array}{l}0.29 \text { AADP } \\
7.59 \text { AADP }\end{array}$ & {$[186,191]$} \\
\hline (1) Ethanol + (2) water+ & $\begin{array}{l}w_{i j}=0.11628 \text { (water- } \\
\text { OH group) } \\
u_{i j}=-0.9978 \\
\text { (water-OH group) }\end{array}$ & 50 & $\begin{array}{l}298.15- \\
423.15\end{array}$ & $\begin{array}{l}2.12 \text { AADP } \\
3.83 \text { AADY }\end{array}$ & [193] \\
\hline (3) $\mathrm{NaF}$ & - & 10 & $\begin{array}{l}350.55^{-} \\
366.15\end{array}$ & $\begin{array}{l}0.34 \text { AADT } \\
6.07 \text { AADY }\end{array}$ & {$[186]$} \\
\hline (3) $\mathrm{NaBr}$ & - & 23 & $\begin{array}{l}351.46- \\
356.45 \\
\end{array}$ & $\begin{array}{l}0.26 \text { AADT } \\
3.19 \text { AADY }\end{array}$ & {$[186]$} \\
\hline (3) $\mathrm{KCl}$ & - & 12 & $352.2-354$ & $\begin{array}{l}0.41 \text { AADT } \\
\text { 4.22 AADY }\end{array}$ & [186] \\
\hline (3) KI & - & 20 & $\begin{array}{l}351.99- \\
356.39\end{array}$ & $\begin{array}{l}0.30 \mathrm{AADT} \\
4.8 \mathrm{AADY} \\
\end{array}$ & {$[186]$} \\
\hline (1) $\mathrm{CO}_{2}+(2)$ Methanol + (3)Water + & & & & & \\
\hline (4) $\mathrm{NaCl}$ & $\begin{array}{l}\text { Only binary } \\
\text { parameters and } \\
\text { CO2-ion }\left(\mathrm{l}_{\mathrm{ij}}\right)\end{array}$ & 33 & $313.6-395.2$ & 14.5AADP & [194] \\
\hline
\end{tabular}

AADP: Average absolute deviation in vapor pressure (see definition in the list of abbreviations) 
AADT: Average absolute deviation in temperature (see definition in the list of abbreviations)

AADY: Average absolute deviation in vapor phase mole fraction of alcohol (see definition in the list of abbreviations)

\section{Conclusion}

This work addresses several issues related to the modeling of mixed solvent electrolytes. In a first part, the methodology of the construction of a SAFT-based electrolyte equation of state is discussed. More specifically, we investigate the meaning of solvation properties and propose using both ionic association and Born term to explain the physical phenomena occurring when bringing an ion from the ideal gas to the pure solvent. We also discuss the role of the dielectric constant and the effect of its functional form on the mean ionic activity coefficient. We conclude with the observation that a salinity dependent dielectric constant is a better choice for describing the individual contributing energies that come into the calculation of the MIAC.

Using the proposed analysis, the ePPC-SAFT electrolyte model initially proposed by Rozmus et al. [113] is further refined, using improved water parameters and a dielectric constant that allows working with mixed solvents. Two ion-specific parameters are fitted on activity coefficients and densities of various alkali halides.

In a final step, the model is evaluated on a larger set of VLE and density data with good success. These data include mixed salts and mixed solvent solutions. In some cases, additional binary interaction parameters had to be adjusted. For this, since the ions are considered to have negligible dispersive interactions, the algebraic average of the hard-sphere diameters was corrected using the approach proposed by Trinh et al. [120], with an addition adjustable parameter $l_{i j}$. The alcohol-water-salt systems was subsequently modeled fairly accurately in a fully predictive way (without any parameter adjustment between alcohol and ions).

Thus, it can be concluded with reasonable certainty that the current model can be used to predict and calculate VLE of mixed-solvent electrolyte systems using solvent-water binary parameters and ionspecific parameters.

\section{Acknowledgements}

This work was supported by the Tuck foundation chair on "Thermodynamics for Biofuels". Financial support from PROSIM company is also acknowledged.

\section{List of abbreviations.}

MIAC: Mean Ionic activity coefficient

AMV: Apparent Molar Volume

VLE: Vapor-Liquid Equilibrium

GC-PPC-SAFT: Group Contribution Perturbed Chain Statistical Associating Fluid Theory

AADP: Average absolute deviation in vapor pressure $=A A D P=\frac{1}{N_{\mathrm{P} \sigma}} \sum_{j}^{N_{\mathrm{P}} \sigma}\left|\frac{\mathrm{P}_{j}^{c a l c}-\mathrm{P}_{j}^{\text {exp }}}{\mathrm{P}_{j}^{\text {exp }}}\right|$

AADT: Average absolute deviation in temperature $=A A D T=\frac{1}{N_{\mathrm{P} \sigma}} \sum_{j}^{N_{\mathrm{T}} \sigma}\left|\frac{\mathrm{T}_{j}^{\text {calc }}-\mathrm{T}_{j}^{\text {exp }}}{\mathrm{T}_{j}^{\text {exp }}}\right|$

AADY: Average absolute deviation of the alcohol in vapor phase mole fraction =

$A A D Y=\frac{1}{N_{\mathrm{y}^{\sigma}}} \sum_{j}^{N_{\mathrm{y}^{\sigma}}}\left|\frac{\mathrm{y}_{j}^{\text {calc }}-\mathrm{y}_{j}^{\text {exp }}}{\mathrm{y}_{j}^{\text {exp }}}\right|$

List of symbols.

$\Delta G_{s} \quad$ Gibbs free energy of solvation. 
$A \quad$ Helmholtz free energy

$T$ temperature

$P \quad$ pressure

$Z \quad$ compressibility factor

$V \quad$ volume

$N_{A} \quad$ Avogadro's number

$N_{S} \quad$ number of association sites

$W_{\mathrm{j}} \quad$ weight of the objective function

$R \quad$ ideal gas constant

$Q \quad$ Quadrupole moment

$n \quad$ number of moles

$m$ molality

$v$ molar volume

$k \quad$ Boltzmann's constant

$x \quad$ mole fraction

$d \quad$ diameter of the pure component

$f_{i} \quad$ fugacity

$\mathrm{m} \quad$ segment number

$J$ pseudo ionization energy

$g(r)$ radial distribution function

$k_{i j} \quad$ binary interaction parameter

$w_{i j} \quad$ cross interaction parameter for association energy

$u_{i j} \quad$ cross interaction parameter for association volume

$l_{i j} \quad$ NAHS interaction parameter

\section{Greek letters}

$\varepsilon \quad$ dielectric constant

$\varphi$ fugacity coefficient

$\gamma_{i} \quad$ activity coefficient

$\sigma \quad$ diameter of ion/segment

$\epsilon / k \quad$ dispersion energy

$\varepsilon^{A B} \quad$ association energy

$\kappa^{A B} \quad$ association volume

$\lambda$ sphere softness

$\rho$ density

$\mu \quad$ chemical potential

\section{Superscript}

exp experimental data

calc calculation from the model

ref reference state

* reference state

\# reference state

res residual (Helmholtz energy)

assoc Association term

disp dispersion term

hc hard chain term

chain chain terms

polar polar term 
NAHS Non-additive hard sphere term

$M S A \quad$ Mean spherical approximation term

Born Born term

\section{Subscript}

$i j \quad$ between component $i$ and $j$

$w \quad$ water

$S \quad$ solvent 


\section{References}

[1] M.J. Hey, D.P. Jackson, H. Yan, Polymer 46 (2005) 2567-2572.

[2] P.M. Gross, Chem. Rev. 13 (1933) 91-101.

[3] R.M. Enick, S.M. Klara, SPE Reservoir Engineering 7 (2013) 253-258.

[4] G.M. Kontogeorgis, G.K. Folas, Thermodynamic models for industrial applications. From classical and advanced mixing rules to association theories, Wiley, Hoboken, N.J., 2010.

[5] G.K. Folas, G.M. Kontogeorgis, M.L. Michelsen, E.H. Stenby, Fluid Phase Equilibria 249 (2006) 67-74.

[6] K. Thomsen, Electrolytes Notes, 2009.

[7] E. Hendriks, G.M. Kontogeorgis, R. Dohrn, J.C. de Hemptinne, I.G. Economou, L.F. Z,îilnik, V. Vesovic, Ind.Eng.Chem.Res. 49 (2010) 11131-11141.

[8] R. Dohrn, O. Pfohl, Fluid Phase Equilibria 194-197 (2002) 15-29.

[9] J.P. O'Connell, R. Gani, P.M. Mathias, G. Maurer, J.D. Olson, P.A. Crafts, Ind. Eng. Chem. Res. 48 (2009) 4619-4637.

[10] S. Gupta, J.D. Olson, Ind. Eng. Chem. Res. 42 (2003) 6359-6374.

[11] P.M. Mathias, Fluid Phase Equilibria 228-229 (2005) 49-57.

[12] K. Huff, AIChE J. 48 (2002) 194-200.

[13] K.S. Pitzer, J. Phys. Chem. 77 (1973) 268-277.

[14] K.S. Pitzer, G. Mayorga, J. Phys. Chem. 77 (1973) 2300-2308.

[15] K.S. Pitzer, G. Mayorga, Journal of Solution Chemistry 3 (1974) 539-546.

[16] F.-X. Ball, H. Planche, W. Fürst, H. Renon, AIChE J. 31 (1985) 1233-1240.

[17] T.W. Copeman, F.P. Stein, Fluid Phase Equilibria 35 (1987) 165-187.

[18] A.H. Harvey, J.M. Prausnitz, AIChE J. 35 (1989) 635-644.

[19] W. Fürst, H. Renon, AIChE J. 39 (1993) 335-343.

[20] K. Aasberg-Petersen, E. Stenby, A. Fredenslund, Ind. Eng. Chem. Res. 30 (1991) 21802185.

[21] A. Anderko, K.S. Pitzer, Geochimica et Cosmochimica Acta 57 (1993) 1657-1680.

[22] J.A. Myers, S.I. Sandler, R.H. Wood, Ind. Eng. Chem. Res. 41 (2002) 3282-3297.

[23] X. Ji, S.P. Tan, H. Adidharma, M. Radosz, Ind.Eng.Chem.Res. 44 (2005) 7584-7590.

[24] B. Maribo-Mogensen, G.M. Kontogeorgis, K. Thomsen, Ind. Eng. Chem. Res. 51 (2012) 5353-5363.

[25] G. Das, S. Hlushak, dos Ramos, M. Carolina, C. McCabe, AIChE J. 61 (2015) 30533072.

[26] C.-C. Chen, C.P. Bokis, P. Mathias, AIChE J. 47 (2001) 2593-2602.

[27] C.-C. Chen, H.I. Britt, J.F. Boston, L.B. Evans, AIChE J. 28 (1982) 588-596.

[28] C.-C. Chen, Pure and Applied Chemistry 59 (1987) 1177-1188.

[29] D.S. Abrams, J.M. Prausnitz, AIChE J. 21 (1975) 116-128.

[30] M.L. Michelsen, J.M. Mollerup, Thermodynamic models. Fundamentals \& computational aspects, 2nd ed., Tie-Line Publications, Holte, Denmark, 2007.

[31] Y. Lin, A.t. Kate, M. Mooijer, J. Delgado, P.L. Fosb $\tilde{A}_{s} 1$, K. Thomsen, AIChE J. 56 (2010) 1334-1351.

[32] K.S. Pitzer (Ed.), Activity coefficients in electrolyte solutions, 2nd ed., CRC, Boca Raton, 1991.

[33] P. Wang, A. Anderko, R.D. Young, Fluid Phase Equilibria 203 (2002) 141-176.

[34] J.J. Kosinski, P. Wang, R.D. Springer, A. Anderko, Fluid Phase Equilibria 256 (2007) $34-41$.

[35] Y. Lin, K. Thomsen, J.-C. de Hemptinne, AIChE J. 53 (2007) 989-1005.

[36] S.P. Tan, H. Adidharma, M. Radosz, Ind. Eng. Chem. Res. 47 (2008) 8063-8082.

[37] M.S. Wertheim, J Stat Phys 35 (1984) 19-34. 
[38] M.S. Wertheim, J Stat Phys 35 (1984) 35-47.

[39] M.S. Wertheim, J Stat Phys 42 (1986) 459-476.

[40] M.S. Wertheim, J Stat Phys 42 (1986) 477-492.

[41] M. Sadeghi, C. Held, C. Ghotbi, M.J. Abdekhodaie, G. Sadowski, J Solution Chem 43 (2014) 1110-1131.

[42] C. Held, T. Reschke, R. Müller, W. Kunz, G. Sadowski, The Journal of Chemical Thermodynamics 68 (2014) 1-12.

[43] T. Reschke, C. Brandenbusch, G. Sadowski, Fluid Phase Equilibria 387 (2015) 178-189.

[44] T. Reschke, C. Brandenbusch, G. Sadowski, Fluid Phase Equilibria 375 (2014) 306-315.

[45] T. Reschke, C. Brandenbusch, G. Sadowski, Fluid Phase Equilibria 368 (2014) 91-103.

[46] C. Held, T. Reschke, S. Mohammad, A. Luza, G. Sadowski, Chemical Engineering Research and Design 92 (2014) 2884-2897.

[47] C. Held, L.F. Cameretti, G. Sadowski, Fluid Phase Equilibria 270 (2008) 87-96.

[48] S. Mohammad, C. Held, E. Altuntepe, T. Kose, G. Sadowski, The journal of physical chemistry. B 120 (2016) 3797-3808.

[49] L.F. Cameretti, G. Sadowski, J.M. Mollerup, Ind. Eng. Chem. Res. 44 (2005) 33553362.

[50] C. Held, G. Sadowski, A. Carneiro, O. Rodríguez, E.A. Macedo, AIChE J. 59 (2013) 4794-4805.

[51] J.R. Loehe, M.D. Donohue, AIChE J. 43 (1997) 180-195.

[52] W. Raatschen, A.H. Harvey, J.M. Prausnitz, Fluid Phase Equilibria 38 (1987) 19-38.

[53] Pinsky, M.L. Takano, K., Computer Aided Chemical Engineering. Chapter 8: Property estimation for electrolyte systems, Elsevier, Denmark, 2004.

[54] B. Maribo-Mogensen, K. Thomsen, G.M. Kontogeorgis, AIChE J. 61 (2015) 2933-2950.

[55] W.G. Chapman, K.E. Gubbins, G. Jackson, M. Radosz, Fluid Phase Equilib. 52 (1989) 31-38.

[56] J. Gross, G. Sadowski, Ind. Eng. Chem. Res. 40 (2001) 1244-1260.

[57] H. Renon, J.M. Prausnitz, AIChE J. 14 (1968) 135-144.

[58] P. Debye, E. Hückel, Physikalische Zeitschrift 24 (1923) 305-309.

[59] E. Waisman, J.L. Lebowitz, The Journal of chemical physics 52 (1970) 4307-4309.

[60] W.G. Chapman, K.E. Gubbins, G. Jackson, M. Radosz, Ind. Eng. Chem. Res. 29 (1990) $1709-1721$.

[61] X. Courtial, N. Ferrando, J.-C. de Hemptinne, P. Mougin, Geochimica et Cosmochimica Acta 142 (2014) 1-14.

[62] A. Shadloo, K. Peyvandi, Fluid Phase Equilibria 433 (2017) 226-242.

[63] S.G. Doozandeh, G. Pazuki, A. Asghar, Journal of Dispersion Science and Technology 33 (2012) 756-762.

[64] M.H. Anvari, G. Pazuki, S.S. Kakhki, B. Bonakdarpour, Journal of Molecular Liquids 184 (2013) 24-32.

[65] G. Das, S. Hlushak, C. McCabe, Fluid Phase Equilibria 416 (2016) 72-82.

[66] B.H. Patel, P. Paricaud, A. Galindo, G.C. Maitland, Ind.Eng.Chem.Res. 42 (2003) 38093823.

[67] H. Jiang, A.Z. Panagiotopoulos, I.G. Economou, Geochimica et Cosmochimica Acta 176 (2016) 185-197.

[68] J.M. Schreckenberg, S. Dufal, A.J. Haslam, C.S. Adjiman, G. Jackson, A. Galindo, Molecular Physics 112 (2014) 2339-2364.

[69] O. Hernández-Garduza, F. García-Sánchez, E. Neau, M. Rogalski, Chemical Engineering Journal 79 (2000) 87-101.

[70] H.-G. Simon, H. Kistenmacher, J.M. Prausnitz, D. Vortmeyer, Chemical Engineering and Processing: Process Intensification 29 (1991) 139-146. 
[71] H. Zerres, J.M. Prausnitz, AIChE Journal 40 (1994) 676-691.

[72] A.H. Harvey, J.M. Prausnitz, Journal of Solution Chemistry 16 (1987) 857-869.

[73] R. Inchekel, J.-C. de Hemptinne, W. Fürst, Fluid Phase Equilibria 271 (2008) 19-27.

[74] P.J. Carvalho, L.M. Pereira, N.P. Gonçalves, A.J. Queimada, J.A. Coutinho, Fluid Phase Equilibria 388 (2015) 100-106.

[75] A. Schlaikjer, K. Thomsen, G.M. Kontogeorgis, Ind. Eng. Chem. Res. 56 (2017) 1074 1089.

[76] Y.-X. Zuo, T.-M. Guo, Chemical Engineering Science 46 (1991) 3251-3258.

[77] A. Galindo, A. Gil-Villegas, G. Jackson, A.N. Burgess, J. Phys. Chem. B 103 (1999) $10272-10281$.

[78] D.K. Eriksen, G. Lazarou, A. Galindo, G. Jackson, C.S. Adjiman, A.J. Haslam, Molecular Physics 114 (2016) 2724-2749.

[79] D. Wei, L. Blum, The Journal of chemical physics 87 (1987) 2999-3007.

[80] C. Held, G. Sadowski, Fluid Phase Equilibria 279 (2009) 141-148.

[81] C. Held, A. Prinz, V. Wallmeyer, G. Sadowski, Chemical Engineering Science 68 (2012) 328-339.

[82] L.F. Cameretti, G. Sadowski, J.M. Mollerup, Ind. Eng. Chem. Res. 44 (2005) 8944.

[83] Z. Liu, W. Wang, Y. Li, Fluid Phase Equilib. 227 (2005) 147-156.

[84] X. Ji, S.P. Tan, H. Adidharma, M. Radosz, J. Phys. Chem. B 110 (2006) 16700-16706.

[85] X. Ji, H. Adidharma, Ind.Eng.Chem.Res. 45 (2006) 7719-7728.

[86] X. Ji, H. Adidharma, Ind.Eng.Chem.Res. 46 (2007) 4667-4677.

[87] X. Ji, H. Adidharma, Chemical Engineering Science 63 (2008) 131-140.

[88] S.P. Tan, H. Adidharma, M. Radosz, Ind.Eng.Chem.Res. 44 (2005) 4442-4452.

[89] B.-S. Lee, K.-C. Kim, Korean Journal of Chemical Engineering 26 (2009) 1733-1747.

[90] J. Rozmus, J.C. de Hemptinne, A. Galindo, S. Dufal, P. Mougin, Ind.Eng.Chem.Res. 52 (2013) 9979-9994.

[91] E. Schmidt, U. Grigull, Properties of water and steam in SI-Units. Zustandsgroben von wasser und wasserdampf in SI-Einheiten, 4th ed., Springer-Verlag, Berlin, 1989.

[92] S. Mohammad, G. Grundl, R. Müller, W. Kunz, G. Sadowski, C. Held, Fluid Phase Equilibria 428 (2016) 102-111.

[93] S. Mohammad, C. Held, E. Altuntepe, T. Köse, T. Gerlach, I. Smirnova, G. Sadowski, Fluid Phase Equilibria 416 (2016) 83-93.

[94] W.B. Liu, Y.G. Li, J.F. Lu, Fluid Phase Equilib. 158-160 (1999) 595-606.

[95] Z.-P. Liu, Y.-g. Li, J.-f. Lu, J. Phys. Chem. B 106 (2002) 5266-5274.

[96] S. Herzog, J. Gross, W. Arlt, Fluid Phase Equilib. 297 (2010) 23-33.

[97] A. Najafloo, F. Feyzi, A.T. Zoghi, Journal of the Taiwan Institute of Chemical Engineers 58 (2016) 381-390.

[98] A. Najafloo, F. Feyzi, A.T. Zoghi, Korean J. Chem. Eng. 31 (2014) 2251-2260.

[99] M. Born, Z. Phys 1 (1920) 45-48.

[100] R. Fauve, X. Guichet, V. Lachet, N. Ferrando, Journal of Petroleum Science and Engineering 157 (2017) 94-106.

[101] J.O. Bockris, H. Egan, Trans. Faraday Soc. 44 (1948) 151.

[102] J.O. Bockris, A.K.N. Reddy, Ionics, 2nd ed., Kluwer Academic, New York, 1998.

[103] J.L. Lebowitz, J.K. Percus, Phys. Rev. 144 (1966) 251-258.

[104] Lin, Yi, Thomsen, Kaj, Development of an equation of state for solution containing electrolytes. PhD, Denmark, 2007.

[105] P. Paricaud, A. Galindo, G. Jackson, Fluid Phase Equilib. 194ÔÇô197 (2002) 87-96.

[106] B. Behzadi, B.H. Patel, A. Galindo, C. Ghotbi, Fluid Phase Equilibria 236 (2005) 241255.

[107] W.R. Fawcett, J. Phys. Chem. B 103 (1999) 11181-11185. 
[108] M. Uematsu, E.U. Frank, Journal of Physical and Chemical Reference Data 9 (1980) 1291-1306.

[109] B. Maribo-Mogensen, G.M. Kontogeorgis, K. Thomsen, The journal of physical chemistry. B 117 (2013) 10523-10533.

[110] I.Y. Shilov, A.K. Lyashchenko, The journal of physical chemistry. B 119 (2015) 10087-10095.

[111] G.H. Haggis, J.B. Hasted, T.J. Buchanan, J. Chem. Phys. 20 (1952) 1452.

[112] B. Maribo-Mogensen, G.M. Kontogeorgis, K. Thomsen, The journal of physical chemistry. B 117 (2013) 3389-3397.

[113] J. Rozmus, J.C. de Hemptinne, N. Ferrando, P. Mougin, Fluid Phase Equilib. 329 (2012) 78-85.

[114] D. Nguyen-Huynh, J.-P. Passarello, P. Tobaly, J.-C. de Hemptinne, Fluid Phase Equilib. 264 (2008) 62-75.

[115] T.-B. Nguyen, J.-C. de Hemptinne, B. Creton, G.M. Kontogeorgis, Fluid Phase Equilibria 372 (2014) 113-125.

[116] D. NguyenHuynh, J.-P. Passarello, J.-C. de Hemptinne, F. Volle, P. Tobaly, The Journal of Supercritical Fluids 95 (2014) 146-157.

[117] P.K. Jog, S.G. Sauer, J. Blaesing, W.G. Chapman, Ind. Eng. Chem. Res. 40 (2001) 4641-4648.

[118] S. Tamouza, J.-P. Passarello, P. Tobaly, de Hemptinne, J. -Charles, Proceedings of the Fifteenth Symposium on Thermophysical Properites 222-223 (2004) 67-76.

[119] Thi-Kim-Hoang TRINH, Prediction of phase equilibria associated with hydrotreating process of biomass by GC-PPC-SAFT Equation of State. PhD, , 1 et 4 avenue de BoisPréau, 92852 Rueil-Malmaison, France, 2015.

[120] T.-K.-H. Trinh, J.-P. Passarello, J.-C. de Hemptinne, R. Lugo, V. Lachet, J CHEM PHYS 144 (2016).

[121] T.B. Nguyen, J.C. de Hemptinne, B. Creton, G.M. Kontogeorgis, Ind.Eng.Chem.Res. 52 (2013) 7014-7029.

[122] J. Rozmus, I. Brunella, P. Mougin, J.-C. de Hemptinne, J. Chem. Eng. Data 57 (2012) 2915-2922.

[123] D. Nguyen-Huynh, J.P. Passarello, J.C. de Hemptinne, P. Tobaly, Fluid Phase Equilib. 307 (2011) 142-159.

[124] J. Rozmus, J.C. de Hemptinne, P. Mougin, Fluid Phase Equilib. 303 (2011) 15-30.

[125] M. Mourah, D. NguyenHuynh, J.P. Passarello, J.C. de Hemptinne, P. Tobaly, Fluid Phase Equilibria 298 (2010) 154-168.

[126] D. NguyenHuynh, A. Falaix, J.P. Passarello, P. Tobaly, J.C. de Hemptinne, Fluid Phase Equilib. 264 (2008) 184-200.

[127] D.N. Huynh, M. Benamira, J.-P. Passarello, P. Tobaly, J.-C. de Hemptinne, Fluid Phase Equilibria 254 (2007) 60-66.

[128] K. Giese, U. Kaatze, R. Pottel*, The Journal of Physical Chemistry 74 (1970) 3718 3725 .

[129] S.O. Derawi, G.M. Kontogeorgis, M.L. Michelsen, E.H. Stenby, Ind. Eng. Chem. Res. 42 (2003) 1470-1477.

[130] J. Gross, G. Sadowski, Fluid Phase Equilibria 168 (2000) 183-199.

[131] S. Ahmed, N. Ferrando, J.-C. de Hemptinne, J.-P. Simonin, O. Bernard, O. Baudouin,

J. Chem. Eng. Data 61 (2016) 4178-4190.

[132] D. Nguyen-Huynh, J.-C. de-Hemptinne, R. Lugo, J.-P. Passarello, P. Tobaly, Ind. Eng. Chem. Res. 50 (2011) 7467-7483.

[133] D. Nguyen-Huynh, J.-C. de-Hemptinne, R. Lugo, J.-P. Passarello, P. Tobaly, Chemical Engineering Research and Design 92 (2014) 2912-2935. 
[134] S.H. Huang, M. Radosz, Ind.Eng.Chem.Res. 29 (1990) 2284-2294.

[135] Y. Marcus, Chem. Rev. 88 (1988) 1475-1498.

[136] L. Blum, W.R. Fawcett, J. Phys. Chem. 96 (1992) 408-414.

[137] J. Wu, J.M. Prausnitz*, Ind. Eng. Chem. Res. 37 (1998) 1634-1643.

[138] B.-S. Lee, K.-C. Kim, Korean J. Chem. Eng. 27 (2010) 267-277.

[139] Y. Liu, M. Hou, G. Yang, B. Han, The Journal of Supercritical Fluids 56 (2011) 125129.

[140] J.-P. Simonin, O. Bernard, L. Blum, J. Phys. Chem. B 102 (1998) 4411-4417.

[141] J.-P. Simonin, J. Phys. Chem. B 101 (1997) 4313-4320.

[142] R.A. Robinson, H.S. Harned, Chem. Rev. 28 (1941) 419-476.

[143] R.M. Diamond, J. Am. Chem. Soc. 80 (1958) 4808-4812.

[144] A. Chremos, E. Forte, V. Papaioannou, A. Galindo, G. Jackson, C.S. Adjiman, Aqueous Solutions 407 (2016) 280-297.

[145] A. Kumar, Can. J. Chem. 63 (1985) 3200-3202.

[146] A. Kumar, J. Chem. Eng. Data 33 (1988) 198-199.

[147] T.G. Pedersen, C. Dethlefsen, A. Hvidt, Carlsberg Res. Commun. 49 (1984) 445-455.

[148] W.J. Hamer, Y. Wu, Journal of Physical and Chemical Reference Data 1 (1972) 10471100.

[149] G. Jones, B.C. Bradshaw, J. Am. Chem. Soc. 54 (1932) 138-150.

[150] E. Vercher, S. Solsona, M. Isabel Vázquez, A. Martínez-Andreu, Fluid Phase Equilibria 209 (2003) 95-111.

[151] J. Kiepe, A. Karine de Araújo Rodrigues, S. Horstmann, J. Gmehling, Ind. Eng. Chem. Res. 42 (2003) 2022-2029.

[152] I.M. Abdulagatov, N.D. Azizov, The Journal of Chemical Thermodynamics 36 (2004) 829-843.

[153] F.A. Gonçalves, J. Kestin, Berichte der Bunsengesellschaft für physikalische Chemie 81 (1977) 1156-1161.

[154] L.A. Romankiw, I.M. Chou, J. Chem. Eng. Data 28 (1983) 300-305.

[155] P.S. Nikam, M. Hasan, R.P. Shewale, A.B. Sawant, Journal of Solution Chemistry 32 (2003) 987-995.

[156] M.K. Karapetyants, V.A. Vasilev, B.V. Mikhailin, Strakhov, V. N.Karapetyants, M. Kh., V.N. Strakhov, Zh. Fiz. Khim. 53 (1979) 207-209.

[157] G.V. Roshkovskii, N.V. Penkina, G.M. Poltoratskii, Viscometric study of the system water - sodium iodide.

[158] D.A. MacInnes, M.O. Dayhoff, J. Am. Chem. Soc. 74 (1952) 1017-1020.

[159] A.B. Zdanovskii, Russ. J. Phys. Chem. 68 (1994) 556-561.

[160] S. Lengyel, J. Giber, H. J, J. Tamas, ACTA CHIMICA ACADEMIAE

SCIENTARIUM HUNGARICAE 40 (1964) 125.

[161] S. Lengylel, J. Tamás, J. Giber, Acta Chim. Hung. (1964) 125-143.

[162] G. Jones, C.F. Bickford, Journal of the American Chemical Society 56 (1934) 602611.

[163] R.E. Gibson, J. Am. Chem. Soc. 56 (1934) 865-870.

[164] F.T. Gucker, D. Stubley, D.J. Hill, The Journal of Chemical Thermodynamics 7 (1975) 865-873.

[165] Mikhajlin, B.V., Vorob'ev, A.F., \& Vasilev, V.A., Zhurnal Fizicheskoj Khimii 56 (1982) 1937-1940.

[166] G. Jones, H.J. Fornwalt, J. Am. Chem. Soc. 58 (1936) 619-625.

[167] A. Michels, J. de Gruyter, F. Niesen, Physica 3 (1936) 346-351.

[168] L.-K. Wang, G.-J. Chen, G.-H. Han, X.-Q. Guo, T.-M. Guo, Fluid Phase Equilibria 207 (2003) 143-154. 
[169] J. Hu, Z. Duan, C. Zhu, I.-M. Chou, Chemical Geology 238 (2007) 249-267.

[170] W. Yan, S. Huang, E.H. Stenby, International Journal of Greenhouse Gas Control 5 (2011) 1460-1477.

[171] D. Tong, J.P.M. Trusler, D. Vega-Maza, J. Chem. Eng. Data 58 (2013) 2116-2124.

[172] R. Sun, J. Dubessy, Geochimica et Cosmochimica Acta 88 (2012) 130-145.

[173] X. Ji, S.P. Tan, H. Adidharma, M. Radosz, Ind. Eng. Chem. Res. 44 (2005) 84198427.

[174] X. Ji, C. Zhu, Geochimica et Cosmochimica Acta 91 (2012) 40-59.

[175] O.L. Culberson, J.J. McKetta, Journal of Petroleum Technology 3 (2013) 223-226.

[176] Thomas D. O'Sullivan and Norman Obed Smith, The Journal of Physical Chemistry 74 (1970) 1460-1466.

[177] Denis Krotov, Weiterentwicklung der Gruppenbeitragszustandsgleichung VTPR zur Beschreibung von Elektrolyt- und Polymersystemen. PhD, 2014.

[178] O.L. Culberson, J.J. McKetta, Journal of Petroleum Technology 2 (2013) 319-322.

[179] A.D. King, C.R. Coan, J. Am. Chem. Soc. 93 (1971) 1857-1862.

[180] J. Lee, II, A.E. Mather, Berichte der Bunsengesellschaft für physikalische Chemie 81 (1977) 1020-1023.

[181] J. Xia, Á. Pérez-Salado Kamps, B. Rumpf, G. Maurer, Ind. Eng. Chem. Res. 39 (2000) 1064-1073.

[182] S.-X. Hou, G.C. Maitland, J.M. Trusler, The Journal of Supercritical Fluids 78 (2013) 78-88.

[183] Chul Soo Lee, Sung Bin Park, and, and Yon Sik Shim, Ind. Eng. Chem. Res. 35 (1996) 4772-4780.

[184] M.A. Clarke, P.R. Bishnoi, Fluid Phase Equilibria 220 (2004) 21-35.

[185] B. Ghalami-Choobar, M. Shekofteh-Gohari, F. Sayyadi-Nodehi, Journal of Molecular Liquids 188 (2013) 49-54.

[186] D. Meranda, W.F. Furter, AIChE J. 18 (1972) 111-116.

[187] D. Meranda, W.F. Furter, AIChE J. 20 (1974) 103-108.

[188] M.C. Iliuta, K. Thomsen, P. Rasmussen, Chemical Engineering Science 55 (2000) 2673-2686.

[189] V.T. Zharov, O.K. Pervukhin, Russ. J. Phys. Chem. 46 (1972) 1130-1132.

[190] J. Yao, H. Li, S. Han, Fluid Phase Equilibria 162 (1999) 253-260.

[191] R.W. Rousseau, J.E. Boone, AIChE J. 24 (1978) 718-725.

[192] N.M. Baron, K.P. Mishenko, Zh. Obshch. Khim. 18 (1948) 2067-2079.

[193] B. Kolbe, J. Gmehling, Fluid Phase Equilibria 23 (1985) 213-226.

[194] Á. Pérez-Salado Kamps, M. Jödecke, J. Xia, M. Vogt, G. Maurer, Ind. Eng. Chem. Res. 45 (2006) 1505-1515. 